Revista de la red interuniversitaria de estudios sobre las literaturas rioplatenses contemporáneas en Francia

16 | 2017

Esnobismos

\title{
Esnobismos de la derecha : Lesca, el fascista irreductible, de Jorge Asís
}

\section{Mariano Sverdloff}

\section{OpenEdition}

\section{Journals}

Electronic version

URL: http://journals.openedition.org/lirico/3786

DOI: $10.4000 /$ lirico.3786

ISSN: 2262-8339

\section{Publisher}

Réseau interuniversitaire d'étude des littératures contemporaines du Río de la Plata

\section{Electronic reference}

Mariano Sverdloff, «Esnobismos de la derecha : Lesca, el fascista irreductible, de Jorge Asís »

Cuadernos LIRICO [En línea], 16 | 2017, Puesto en línea el 09 octubre 2017, consultado el 19 abril 2019. URL : http://journals.openedition.org/lirico/3786 ; DOI : 10.4000/lirico.3786

This text was automatically generated on 19 April 2019

\section{(c) $(1) \ominus$}

Cuadernos LIRICO está distribuido bajo una Licencia Creative Commons Atribución-NoComercialSinDerivar 4.0 Internacional. 


\title{
Esnobismos de la derecha : Lesca, el fascista irreductible, de Jorge Asís ${ }^{1}$
}

\author{
Mariano Sverdloff
}

\section{Introducción : dandismos de la violencia}

1 La distinción, en tanto producto del cambiante juego de las apariencias sociales, es por definición frágil. De allí que el dandismo -intento de singularización- y el esnobismo singularización considerada falsa o mimética- compartan un espacio limítrofe. En tanto estrategia de distinción social, el dandismo está constantemente amenazado por la corrosión del desenmascaramiento : fácilmente el dandi puede convertirse en un esnob, en un falso dandi, puede ser "esnobeado». Es en virtud de esta cercanía entre «verdadera » $\mathrm{y}$ «falsa » distinción -ya tematizada en The Book of snobs de William Makepeace Thackeray (1848)-, que el Dictionnaire du dandysme (2016) compilado por Alain Montandon incluye la entrada «Snobisme», y que el Dictionnaire du snobisme (1958) de Philippe Jullian incluye la entrada « Dandy $»^{2}$.

2 El hecho de ser esnobeado puede entenderse como la caída de la máscara teatral, como la explicitación del mecanismo, fallido o develado, de la construcción de la imagen. El dandi de hoy puede ser el esnob de mañana, porque en el juego delicado de la autoconstrucción para la mirada de los otros, basta un pequeño cambio de contexto para que la supuesta distinción caiga en el ridículo (o incluso, como veremos, en la ignominia). En ese caso la distinción muestra su ambivalencia: es una singularidad que vive de las apariencias sociales a las cuales, sin embargo, dice rechazar ${ }^{3}$.

3 Se trata de una mecánica conocida. Pensemos en Victoria Ocampo, quien, tal como recuerda Mariano García ${ }^{4}$ en este mismo número de Cuadernos LIRICO, fuera « esnobeada » por Virginia Woolf en un episodio proustianamente paradigmático; y a quien Philippe Jullian incluyera en su Dictionnaire de snobisme a título de exponente intelectual, "parisino", del esnobismo de las clases altas argentinas, ellas mismas por lo demás devotas, según se lee en la entrada « Argentine » del diccionario, de un risible esnobismo europeizante ${ }^{5}$. 
4 Ahora bien, así como existen estrategias de distinción que tienen por objeto la imitación de las clases altas (en particular de la nobleza, según sugiere la probable etimología de "snob»), y que se inscriben en una compleja dinámica de diferenciaciones y aproximaciones entre aristocracia y burguesía, existen también -es el tema de este trabajo- estrategias de distinción cuyo objeto de mímesis es la violencia. La originalidad de Lesca, el fascista irreductible (2000) de Jorge Asís reside en que describe el mundo, bastante menos explorado, de los escritores fascistas, especie particular de « petimetres ", tal como los llama la novela (recordemos que "petimetre», según la Real Academia Española significa «Persona que se preocupa mucho de su compostura y de seguir las modas »).

5 Estos individuos son por lo general hombres de letras que se han dedicado a celebrar la violencia y que desde ese lugar han construido una cierta singularidad; casos representativos podrían ser Filippo Tommaso Marinetti, Pierre Drieu la Rochelle, hasta cierto punto Gabriele D'Annunzio, cuyas biografías figuran, por lo demás, en el diccionario de dandis preparado por Montandon. El objeto de su mímesis es el soldado, la guerra, una cierta aristocracia bárbara que se opondría al mundo burgués de la convención y la masificación. En el imaginario del dandi fascista, el «heroísmo guerrero ", siempre masculino y de claras tendencias misóginas, ha suplantado a la androginia finisecular: podría decirse que estos petimetres son los herederos brutalizados de esos héroes, aventureros o soldados (César, Catilina o Byron, por ejemplo) a los que suelen aludir las definiciones decimonónicas de dandi ${ }^{6}$. Son una suerte de exacerbación militarista del famoso dictum baudelaireano : « Le dandysme est le dernier éclat d'héroïsme dans les décadences $»^{7}$.

6 Abundan para esta clase de escritores, tal como puede observarse en el caso de Drieu la Rochelle, intentos de comprensión ${ }^{8}$. Son -se supone- grandes malditos que, como han ido hasta el fondo, albergaron en sí una cierta violencia histórica, y que si se extraviaron o cayeron en el error, es porque detrás de la máscara está el gran secreto del convulsionado siglo XX, al que habrían mirado de frente. Es un retrato « romántico», sublime, podría decirse.

7 Lejos estamos del juego manierista y esteticista del dandi fin-de-siècle, compuesto de fintas, parodias y refracciones, juego a partir del cual, como sucede con Des Esseintes, el dandismo se define en función de su autorreflexividad irónica. En este caso detrás de la apariencia, de la máscara, habría un gran secreto, acaso el enigma del nihilismo; si el esteta fascista es criminal, es porque ha experimentado la Guerra, la Muerte, el Destino, la Nada, la Esencia de Occidente, la Historia, etc. Ha sido, como dicen infinidad de presentaciones periodísticas de Ernst Jünger -un caso particularmente exitoso de la promoción de este tipo de personajes- « testigo del siglo »".

8 Claro que tal lectura mitológica exige, ante todo, una cierta credulidad: los hombres de letras fascistas serían idealistas extraviados que han asumido como propio un proyecto destructor, sí, pero de algún modo auténtico, al que habría que interrogar con extrema seriedad, dado que se trata de una experiencia trágica pero filosóficamente significativa. Cuanto más condenables, por tanto, más atrayentes. Como su criminalidad es profundamente " histórica», sería extremadamente interesante, casi chic, interrogar el mal que hay en ellos. A tal lógica responde, por ejemplo, un libro como Drieu la Rochelle: du dandy au nazi (1992[1978]) de Dominique Desanti ${ }^{10}$. 
9 Ahora bien : no es este en absoluto el punto de vista que propone Asís, quien, por el contrario, se acerca a las estrategias de distinción de los escritores fascistas -« canallas », según el léxico de la novela-, desde la perspectiva corrosiva de la sátira.

10 Una sátira que « esnobea » al petimetre fascista, y lo convierte, apenas, en un subtipo particularmente abyecto- del « reventado » asisiano ${ }^{11}$.

\section{Charles Lesca, o de las lógicas de la distinción fascista}

11 Para acercarse a la Francia de los '30, Asís toma el camino de la sátira y exporta a Europa su propio imaginario " reventado ", de fuertes inflexiones arltianas. Se distancia así de la interrogación acerca de cómo influyó el fascismo en la Argentina, que es, como lo demuestran Leonardo Senkman y Saúl Sosnowski en Fascismo y nazismo en las letras argentinas (2009) la aproximación más extendida al tema en la literatura nacional. Como ya se advierte desde Los reventados (1974), narración ambientada en la llegada de Perón a Ezeiza, el "reventado" asisiano es ante todo un pícaro que, en el contexto de una empresa política mayor, lucha por su imposición en tanto individuo. Así, en Lesca... existe una gran conspiración paranoica mundial (la que narran, por ejemplo, Los protocolos de los sabios de Sión o algunas novelas de Hugo Wast), existe una conspiración de la gran política (la búsqueda fascista de la toma del poder) y existe otra conspiración, más personal, a través de la cual cada « canalla » lucha por su preeminencia dentro del campo intelectual y político. El « reventado » conduce una conspiración personal adentro de la conspiración de la gran política, un complot adentro del complot, que a menudo tiene un final trágico o fracasado. Su singularidad, su distinción frente a los otros complotados, se juega en ese tramolleo incesante para cooptar voluntades en beneficio propio. "Deslizarse » es el verbo que utiliza Asís en Lesca... para definir esta actividad de autopromoción, término que por lo demás el narrador, con notable ironía, aplica tanto al « fascista irreductible » Lesca como a Victoria Ocampo.

12 Ha escrito Horacio González, en un artículo que integra el dossier dedicado a Asís de la revista $E$ l ojo mocho (uno de los primeros intentos consecuentes, junto con las reflexiones de Josefina Ludmer en Aquí América latina y el preciso estudio de Nidia Burgos, de leer la excentricidad de su obra) : "La literatura picaresca, contracara específica de la literatura épica, reposa en una reflexión sobre el honor. Solo que lo somete previamente a una investigación escéptica sobre su propio origen oscuro, depredador e incluso cruento $»^{12}$.

13 En este caso, el « honor » cuyo origen se investiga es la distinción o preeminencia del escritor fascista. A través de una serie de tópicos propios de la sociología literaria se trama una fábula sobre la guerra de posiciones dentro del campo intelectual y político del ascendente fascismo francés : tráfico de influencias, redes de circulación transatlánticas entre París y la « recóndita América Latina », dinero, aprovechamiento de las ambiciones intelectuales de los otros, políticas de camarilla, vaivenes entre el espacio de la bohemia y la alta sociedad, intercambio de dones y contradones, editores, opinión pública, tensiones entre los polos político, literario y económico.

14 Ahora bien : Asís materializa estas dinámicas, un poco en el tono de Historia universal de la infamia (1935), a través de la ficcionalización de la vida de una figura histórica menor, el franco-argentino Carlos Hipólito Saralegui Lesca, también conocido como Charles Lesca o Lescat. Nacido en Buenos Aires en 1887, hijo de inmigrantes vascos en la Argentina, fue el 
próspero heredero de un negocio de exportación de carne vacuna. Voluntario durante la primera guerra mundial en el ejército francés, conocerá a Maurras y se vinculará con la Action Française y con demás grupos de extrema derecha, nacionalistas y fascistas. Será administador (a partir de 1936) y director (a partir de 1943) del periódico fascista y antisemita Je suis partout, uno de los órganos de prensa más emblemáticos de la colaboración, aunque tampoco se privará de dar a conocer sus ideas en otras publicaciones ultraderechistas, como Le cri du peuple. En 1940, durante la «drôle de guerre » es detenido junto con Alain Laubreaux por órdenes de Georges Mandel, ministro del interior del gobierno de Paul Reynaud, y es liberado poco después de la firma del armisticio y la asunción de Pétain : narrará esta experiencia en el libelo antisemita Quand Israël se venge, publicado en 1941. Colaboracionista convencido, integra el comité central de la Légion des volontaires français contre le bolchévisme, batallón voluntario a las órdenes de los nazis. En 1944, después de la liberación de Francia, se escapa hacia Alemania, y finalmente, tras recalar en España y en el Uruguay llega a la Argentina en 1946, desde donde ayuda a organizar las líneas de escape (que contaban con el apoyo de Perón) que permitirán la fuga de otros fascistas europeos, entre ellos el rexista belga Pierre Daye. Lesca es condenado a la pena capital por la Cour de cassation de París en 1947, por « inteligencia con el enemigo », pero las autoridades argentinas no lo extraditan y muere en la Argentina en 1948. Paralelamente a esta carrera como político y publicista del nazifascismo, Lesca tomará parte activamente, secundando al hispanista Ernest Martinenche, en la organización, en las primeras décadas del siglo XX, de las redes de intercambio culturales, institucionales y académicos entre Francia y América Latina. Será la duplicidad de este perfil de fascista y pasador cultural entre Francia y América Latina el centro de la ficcionalización de la novela de Asís.

15 «[D]on Charles Lesca, fasciste irréductible autant que calme, sous son grand chapeau américain $»^{13}$ : tal es la descripción que da Robert Brasillach del personaje histórico en Notre avant-guerre (1941), cuando relata con tierna melancolía la " camaraderie unique » de «cet étonnant journal »" el diario Je suis partout. Descripción que Asís tomará como epígrafe para su novela y que narrativizará en clave de picaresca «reventada»: la irreductibilidad y la tranquilidad del Lesca asisiano se apoyarán, ante todo, en las divisas que produce el negocio agroexportador, metaforizado como " emitir cadáveres de vaca " (Asís 2000 : 43). Rastacuero tardío, pariente lejano, si se quiere, de esos argentinos " gais et bien payants ${ }^{15}$ entre los cuales era tan popular, para desesperación de Bardamu, la Musyne de Voyage au bout de la nuit, el Lesca asisiano intentará triunfar en una Europa de « intelectuales miserables...que tenían tanta hambre como lecturas» (Asís $2000: 29$ ). El «fascista irreductible» es -se nos dice en la novela- un argentino rico tan interesado como Victoria Ocampo en la singularidad que implica un lugar relevante en el campo intelectual francés.

16 Como si se tratara de la materialización ficcional, en clave grotesca, de esas dinámicas que Gisèle Sapiro, siguiendo a Pierre Bourdieu, analiza en La guerre des écrivains (1999) dentro del campo intelectual francés de los años de la Ocupación, Lesca narra las luchas de los « canallas » por la distinción. Por ejemplo :

Si Lesca trataba con aprensión a Massis era por motivos menos enaltecedores y geopolíticos. Solía irritarle, como a Drieu, que Henry Massis promoviera hasta la exasperación al ausente Robert Brasillach (..). Les indignaba a los canallas odiadores que Massis hubiese puesto a disposición del odiado Brasillach los estantes de su biblioteca, su documentación completa e invalorable. Que Massis le hubiese cedido a Brasillach los imprescindibles contactos que mantenía con los influyentes 
personajes del nacionalismo activo de todos los confines de Europa. Con el respaldo de Massis, según los canallas, el « pederasta » catalán aprovechaba para crecer por su cuenta. Lo usaba para capturar invitaciones a los congresos y seminarios, traducciones de sus artículos, protagonismo personal amparado por la cautivante causa fascista. (Asís $2000: 85$ )

17 Una distinción que no se apoya en la construcción de un valor literario autónomo. Porque, desde la perspectiva "reventada ", el valor literario poco tiene que ver con la forma ; más bien parece ser apenas el producto de las condiciones (siempre heterónomas en relación al valor estético) de legitimación del campo literario. La preeminencia simbólica es el resultado de la confluencia inestable de factores como la ideología, el dinero, las luchas por el prestigio y las bajas pasiones personales. La posición literaria puede comprarse por "monedas", vocablo este que se repite obsesivamente a lo largo de la novela. De allí la importancia de la única mención a Borges en la novela, que sirve, justamente, para sancionar, con su arte de injuriar, la conversión de la literatura en pura materia monetaria, en baratura. Borges, utilizado a menudo en el campo cultural argentino para sancionar la idea de una literatura " pura ", " autónoma ", " elevada ", « universal», sirve aquí para afirmar exactamente lo contrario, para convertir a la literatura en monedas insignificantes, en « capdevilas » :

Capdevila era utilizado, por la inspiración de Borges, como medida de lo insignificante. Álvarez Tuñón, otro discípulo de Lugones, contaría años después que Borges decía :

-Ese cuento de Leónidas Barletta no vale ni siquiera un 'capdevila'. Por el de Álvaro Yunque hasta dos 'capdevillas' se puede pagar (Asís $2000: 79) .{ }^{16}$

En este sociología reventada del fascismo, todo se compra y todo se vende, todo es especulación económica. El narrador revierte contra los «canallas » la acusación de venalidad que el discurso antisemita lanza contra los judíos. Es por eso que Lesca, hábil administrador, les aconseja a los redactores de Je suis partout poner sus ganancias en oro, « para mantener a resguardo el capital, porque los judíos les habían dejado una serie de magistrales enseñanzas, a través de sus destrucciones financieras » (Asís 2000 : 116). Más allá de todo valor literario autónomo, pero también más allá de todo "idealismo » fascista, lo que cuenta de verdad es la capacidad de "deslizamiento », causa y efecto de las «monedas». Bien lo saben los «perspicaces mercaderes» (Asís 2000: 157) del «próspero negocio del antisemitismo » (Asís 2000 : 107), los editores como Arthème y Jean Fayard, Robert Denoël o Bernard Grasset, quienes le proporcionan a los canallas « la mágica gloria del libro impreso » (Asís $2000: 157)^{17}$, esto es, una presencia en el mercado de los valores literarios. Digamos por lo demás que, desde la perspectiva "reventada ", este carácter transaccional excede ampliamente al campo fascista y se aplica también a los escritores liberales o comunistas: a Victoria Ocampo, por ejemplo, quien podía comprar intelectuales « aún baratos y accesibles » (Asís $2000: 74-5)$, gracias al « cencerro seductor de sus monedas cautivantes"; a Sartre, a quien se le atribuye un "plácido sentido de la oportunidad " (Asís $2000: 14$ ). Tanto «boches » como «bolches ", fascistas como antifascistas, apuestan su prestigio literario en el « casino ideológico » (Asís 2000 : 14), con resultados inciertos. Pueden obtener la ignominia, el olvido, « la marginalidad desechable de los malditos de verdad » (Asís $2000: 16$ ) o el triunfo, como la izquierda y su literatura, « en el combate semántico del reconocimiento y la dignidad (Asís 2000 : 13). La indistinción entre derecha e izquierda es una derivación de esta visión reventada : en el campo literario solamente hay luchas, "triunfadores » $\mathrm{y}$ « triunfados », para retomar los términos que Asís utiliza en Carne picada (1981). 
19 El valor que organiza las distinciones en el campo literario «canalla» es el antisemitismo. De hecho el propio antisemitismo es descripto como una «moda » o « última onda » (Asís 2000 : 25), esto es, como un código en torno del cual se organizan una jerarquía estética y una cierta consideración social, comparables, según el indirecto libre del narrador, a tantas otras modas que llegarán con retraso a África o América Latina. Los escritores fascistas son esnobs del odio y de la guerra que desean sigularizarse en esta «moda » del antisemitismo. De allí que el antisemita Pierre Drieu la Rochelle quien por lo demás se dará muerte con un suicidio « estético » (Asís 2000 : 161)- reciba una y otra vez el epíteto de "petimetre ». En la misma lógica de autopromoción y distinción a través del antisemitismo se inscribe el éxito editorial de Quand Israël se venge. En este libro, editado por Grasset en 1941, el « irreductible » narra en tono épico « los pesares módicos» de su "mitificado cautiverio» (Asís 2000 : 157), esto es, la breve detención durante la «drôle de guerre », bajo el gobierno de Paul Reynaud. Recordemos que Lesca fue arrestado el 29 de mayo de 1940 junto con Alain Laubreaux, a causa de los artículos antirrepublicanos y antisemitas aparecidos en Je suis partout, y fue internado en el campo de Gurs -irónicamente junto a comunistas y anarquistas, sobre todo republicanos españoles-, de donde fue liberado el 28 de junio de 1940.

Un documento permite comprobar lo provechosa que esta estregia de autopromoción fue para el Lesca histórico en que el se inspiró la novela de Asís. Se trata de Phönix oder Asche? , publicado en 1942 por Bernhard Payr, « experto » en literatura francesa y funcionario en París del Amt Rosenberg, el organismo de propaganda y "cultura » nazi que respondía al doctor Alfred Rosenberg. El texto, un informe sobre la vida literaria francesa que contiene una pequeña antología, se inscribe en la construcción nazi de la imagen de Francia, y desde esa perspectiva destaca a los autores (entre ellos Lesca) que serían compatibles con el proyecto nazi de "unificación europea ${ }^{18}$. Se trata de un texto fundamental para entender las estrategias literarias y culturales nazis durante la ocupación, dado que fue escrito por un protagonista directo de los acontecimientos (recuérdese que a Payr, quien llegaría en 1943 a ser jefe del Amt Schriftum, el organismo encargado de la política literaria del Reich, se le atribuye la primera lista de censura literaria durante la ocupación - llamada, precisamente « lista Bernhard »-, que incluía a 143 obras, sobre todo de autores alemanes y franceses antinazis). En 1984 Gérard Loiseaux publicó una traducción del libro de Payr y una detallada investigación de su contexto, La littérature de la défaite et de la collaboration d'après Phönix oder Asche? (Phénix ou cendres ?) de Bernhard Payr. Citemos, en la traducción de Loiseaux, la parte referida a Lesca, donde el «experto en literatura francesa » Payr no ahorra elogios para el compromiso antisemita del autor de Quand Israël se venge:

Parmi toutes les œuvres qui paraissent aujourd'hui en France sur le thème de la question juive, un récit vécu que Charles Lesca a publié sous le titre Quand Israël se venge occupe une place particulière. Il s'agit là du récit d'un collaborateur de l'hebdomadaire Je suis partout, déjà si souvent mentionné ici. Lesca a été arrêté en mai 1940 en même temps que son camarade Alain Laubreaux sous le prétexte de menées antinationales, mais en fait uniquement à cause de ses courageuses publications antisémites, sur ordre du ministre juif de l'intérieur, Georges Mandel. Il fut traîné comme prisonnier à travers toute la France. Dans l'introduction le lecteur apprend l'essentiel des motifs de cette mesure inouïe, qui n'était possible que sous le régime de la terreur juive en France. Dans les notes de journal publiées par Lesca, se trouve décrit le calvaire de cet homme arrêté illégalement pendant les 25 jours, riches en aventures, de sa déportation de Paris à Gurs, un camp autrefois destiné aux Espagnols rouges internés. Il relate aussi les rencontres avec d'autres 
détenus de tous les horizons politiques, avec les gardiens, avec la population civile en exode sans oublier de nombreux incidents et événements, qui donnent à cette relation d'un transport de prisonniers constamment en fuite devant l'avance ennemie, un ton particulièrement dur et amer. Mais ce qui accablait le plus l'auteur, c'était de penser à l'infâme accusation de crime de haute trahison lancée par des Juifs assoiffés de vengeance contre un authentique patriote. Son crime avait seulement consisté à vouloir le meilleur pour son pays, lorsqu'il proclamait déjà ses opinions antisémites à une époque ou les Juifs étaient encore en pleine possession du pouvoir. Grâce à l'intervention du nouveau gouvernement français, Lesca et Laubreaux furent enfin libérés le 28 juin de ces tortures morales. Ces deux détenus innocents avaient plus souffert de cette épreuve morale que de leurs misères physiques et que de la honte d'avoir à partager la baraque des 'isolés', c'est-à-dire des espions et des traitres à leur pays. Dans une partie annexe très détaillée, l'auteur soumet à ses lecteurs une série de documents très officiels d'où ressort l'illégalité de son arrestation. Au nombre de ces documents se trouve aussi l'incroyable rapport de police, sur la foi duquel on a procédé à l'arrestation des deux collaborateurs de l'hebdomadaire antisémite. Ce document illustre bien la soif de vengeance des Juifs et on doit le considérer comme un exemple dissuasif des méthodes sans scrupule du judaïsme international. ${ }^{19}$

21 Como puede verse en este delirante informe, desde la perspectiva del ocupante nazi, como ya lo era en gran medida para los fascistas franceses, el antisemitismo es un valor literario. La novela de Asís ficcionaliza en clave « reventada » este universo mental, en el que la lucha por la diferenciación en el campo literario impulsa la radicalización. Dinámica que se explicita en Notre avant-guerre de Brasillach : «Lorsque notre travail était fini, nous allions boire quelques demis au bistrot du coin, avec Charles Lesca, qui, sous ses airs tranquilles, ne trouvait jamais le journal trop violent $»^{20}$. El antisemitismo es ideológico pero también responde a la lógica de legitimación simbólica dentro del campo literario («Les prises de position politiques des écrivains obéissent en effet à des logiques qui n'ont pas la politique pour seul principe. Les intéressés eux-mêmes les dissocient d'ailleurs rarement de leurs pratiques professionnelles: leur propension à s'engager dépend aussi de la manière dont ils conçoivent leur métier $»^{21}$, dice Sapiro). Asís, quien evidentemente consultó documentos originales de esta época, y probablemente los haya discutido con el historiador nacionalista Enrique Zuleta Álvarez ${ }^{22}$, identifica estas dinámicas y plantea en su ficción a Brasillach, figura dominante de Je suis partout, como arbiter elegantiarum de esta institución literaria en la que es mejor considerado quien más odia a los judíos :

Brasillach administraba la palabra con un autoritarismo conceptual a la última moda antisemita de la temporada. Perfectamente podía tratarse de una pasión que se presentaba con la máscara movilizadora del patriotismo (Asís $2000: 15$ )

De allí que para desplazar a Brasillach, el Lesca ficcional deba ubicarse «todavía más a la derecha (...) aunque resultaba casi imposible porque entonces ser más derechista que Brasillach podría convertirse en un osado atributo de la imaginación » (Asís 2000 : 21).

23 Ahora bien : es a partir de esa centralidad del « antisemitismo como virtud literaria » que el Lesca asisiano intenta posicionar a la literatura argentina en un lugar dominante del sistema literario fascista internacional. La novela narra los planes de producción de valor literario de "Carlitos conspirador ", mote que recibe Charles Lesca en alusión a Carlitos Gardel, otro triunfador de las relaciones franco-argentinas.

24 A partir de los años '90, la sociología de las intelectuales, con los trabajos de Pierre Bourdieu, Pascale Casanova y la mencionada Sapiro, entre otros, ha estudiado la circulación internacional de ideas, el rol de los imperialismos literarios, las relaciones 
centro-periferia, o la constitución de un campo literario de alcance mundial. Lesca parece reactualizar de forma caricatural y «canalla " estos planteos. En tanto "traficante ideológico » (Asís 2000 : 19) entre Francia y América Latina, conocedor de la lógica de los intercambios « reventados »-diferente en este punto de Rebatet (apenas, « un otario », un «turrito»), o de Brasillach, (un « romántico»), el « irreductible» intentará invertir la relación centro-periferia y disputarle a París su lugar de capital de las letras fascistas. Lesca, enormemente confiado en la "virtud literaria del antisemitismo", supone que gracias "a sus sorprendentes intelectuales mejor alimentados» (Asís 2000: 29) la Argentina está en condiciones de imponer su « arrebatadora » literatura fascista. Frente a Charles Maurras, Leopoldo Lugones, quien además, según Lesca, se adelantó a Mussolini (Asís 2000 : 66). Desde esta perspectiva, escritores como Manuel Gálvez, los « hermanitos [Julio y Rodolfo] Irazusta » (Asís $2000: 19$ ), el « misterioso e inquietante [Juan E.] Carulla » (Asís 2000 : 22), Monseñor Gustavo Franceschi o el Padre Julio Meinvielle deberían ocupar el centro de la escena literaria. De allí que Lesca llegue a exagerar hasta el absurdo las « virtudes literarias antisemitas » del autor de Entre la Iglesia y el Tercer Reich (1937) : « En su relato, Me[i]nvielle era un batallador infatigable que desayunaba judíos, un antisemita sin parangón que prefería cortarlos en cuadraditos como a la mortadela ». (Asís 2000 : 35)

El narrador parece solazarse con los corolarios ridículos del canon lesquiano. Se burla de la autopercepción enaltecedora que Lesca tiene de su best-seller Quand Israël se venge, claramente inferior en calidad literaria, según el propio narrador, a las diatribas de Céline y Rebatet. O de la idea extraordinaria, enunciada por el « irreductible », de que Hugo Wast es mejor escritor que Céline, bien que este último merezca especial consideración en virtud de su antisemitismo. "Hugo Wast en la vanguardia explícita del antisemitismo literario » (Asís 2000 : 36) : la conjunción de « Hugo Wast » y « vanguardia » en una misma oración, dada "la indiscutible ausencia de valores literarios $»^{23}$ de la obra de Gustavo Martínez Zubiría, resulta sorprendente para el lector actual. Pero estas afirmaciones humorísticas reponen la centralidad del fascismo en la literatura de entreguerras; subrayan, por ejemplo, el ámbito ideológico que nutrió al doctor Destouches, ámbito del que suelen aislarlo lecturas demasiado « literarias ». Y nos recuerdan de paso que, en la lejana Argentina, había también escritores dispuestos a luchar por la «causa justa y noble » del antisemitismo, entre ellos el hoy olvidado director de la Biblioteca Nacional, Hugo Wast, quien era, según Manuel Gálvez, el único que podía vivír de lo que ganaba con sus libros ${ }^{24}$.

\section{Valor literario y virilidad fascista}

26 El narrador de la novela, cómodamente asentado en el machismo denigratorio de la picaresca rioplatense, describe una sociabilidad fascista que se basa en el menoscabo de la virilidad del otro. De este modo, Lesca « esnobea », a partir de su posición preeminente, a los otros escritores fascistas: los considera apenas, en tanto impotentes, hambreados o pederastas, admiradores ratés de la violencia. El narrador, que aporta, para usar la categoría de Rodríguez y Alfón Scafati, toda su carga de « crudismo » picaresco ${ }^{25}$, reduce a los petimetres fascistas a una simple corporalidad fracasada, a una frustración elemental : las diatribas de Rebatet, que anda siempre famélico, dispuesto a escuchar a Lesca con tal de recibir un plato de comida, están " condicionadas por sus prematuras eyaculaciones » (Asís 2000 : 67) ; Drieu es un eyaculador precoz e impotente que mitifica sus conquistas amorosas, apenas un « gil » (el autor, justamente, de la novela Gilles); a Brasillach se lo 
clasifica, en general, como "un pederasta catalán ». Asís desemboca aquí, por la vía oblicua del machismo rioplatense, en uno de los núcleos centrales de la estética y la ética fascista, la virilidad, tema al que se han referido numerosos estudios desde los años '70, entre los que podemos mencionar Männerphantasien (1977-8) de Klaus Theweleit, Reproductions of Banality: Fascism, Literature, and French Intellectual Life (1986) de Alice Yaeger Kaplan y Das Bild des Mannes. Zur Konstruktion der modernen Männlichkeit (1997) de George L. Mosse ${ }^{26}$. El fascismo plantea un vínculo indisoluble entre guerra y masculinidad. Dice Enzo Traverso en À feu et à sang: De la guerre civile européenne 1914-1945 (2007) :

La guerre devient le lieu de réalisation de cet archétype mâle qui se transforme en virilité agressive. La masculinité devient synonyme de force, courage, virilité, énergie, volonté d'action, solidité des nerfs, mais aussi droiture morale, générosité, beauté, noblesse d'esprit, idéalisme. Ainsi esquissé, l'idéal masculin est inévitablement opposé, comme une antinomie absolue et irréductible, à tous les symptômes de la «décadence»: faiblesse, lâcheté, immoralité, laideur, monstruosité. Ces marques néfastes et méprisables se concentrent alors, nous l'avons vu, dans les outsiders juifs et homosexuels. ${ }^{27}$

Ahora bien, lejos de estos arquetipos masculinos, los escritores fascistas « canallas » son pederastas, impotentes o eyaculadores precoces. Están enfermos, como Maurras quien es -en las maliciosas palabras del crítico musical Rebatet- un "patético sordo " (Asís 2000 : 51), o como el propio Lesca, quien tiene problemas cardíacos y termina siendo atendido en Buenos Aires -irónicamente- por un médico judío. Los cuerpos de los intelectuales « canallas » en nada se parecen a los cuerpos íntegros y germinativos de la propaganda y el arte nazis, triunfantes en la guerra, pero también en una sexualidad victoriosa que, concebida como un puro pasaje al acto sin sublimación ni melancolía, asegura la reproducción de la raza. ${ }^{28}$ Los Rebatet o los Brasillach no son esculturas de Arno Breker o pinturas de Walther Hoeck, sino miserables que se hacen pagar el gigot d'agneau en el «bodegón de Boedo de Denfert Rochereau (Asís 2000: 32). Más fantaseadores de masacres que ejecutores directos, son "giles ", «turritos » y «otarios », como dice el narrador en lengua arltiana, merecedores, por tanto, de un desprecio equivalente al del farmaceútico Ergueta contra Erdosain ( ¿ ¿Te pensás que porque leo la Biblia soy un otario ? (...) -Rajá, turrito, rajá. », rezan las celebres líneas de Los siete locos) ${ }^{29}$. Si Jünger hablaba en Der Kampf als inneres Erlebnis (El combate como experiencia interior, 1922) de la guerra moderna como un goce sexual que se daría bajo el "signo de Eros, el desenfrenado» ( im Zeichen Eros, des Entfesselten $»^{30}$ ), el crítico musical Rebatet es definido por el narrador como « un militarista que desconocía la manera de cargar un arma» (Asís 2000 : 35), al que la lectura de Bagatelas para una masacre, le provocaba un placer « equiparable al que sentía cuando penetraba a [su esposa] Veronique » (Asís 2000 : 68). De hecho, las únicas escenas de violencia que se narran con detalle son el duelo suspendido antes de empezar entre Brasillach y Lesca, y los «tortazos circunstanciales » que Lesca le da a Noelle, la prostituta con la que huye de la épuration y recala en la Argentina.

28 El «reviente » es ante todo una forma de individualismo. Más allá de toda idea de Männerbund fascista, de camaradería viril como la que añoraba Brasillach en Notre avantguerre, los fascistas se desprecian unos a otros. En este punto, Lesca... coincide con el tono del Journal de Drieu, mencionado varias veces a lo largo de la novela. Publicado póstumamente en 1992, el texto, de una tonalidad claramente solipsista, abunda en notas misóginas y acusaciones paranoicas de pederastia a diversos enemigos políticos y literarios (de hecho, el narrador de Lesca... comenta un pasaje en el que Drieu acusa 
Brasillach de "conflictivo pederasta catalán » (Asís 2000: 11), expresión que es una traducción libre de la fórmula de Drieu «Quant à Brasillach, c'est la faconde des pédérastes de Barcelone. ${ }^{31}$ ). El narrador « crudista » se complace en expandir, mediante el indirecto libre, los insultos de unos fascistas a otros : los de Drieu contra Brasillach, los de Lesca contra Drieu y Brasillach, los de Rebatet contra Maurras (de allí que se cite una ocurrencia de Les décombres de Rebatet, quien llama a la Action Française «Inaction Française ", a causa de sus hesitaciones ante el compromiso con el ocupante nazi). Más aún, la novela parece acercarse aquí a una modalidad extendida en los años ' 30 y ' 40 , que es la reducción del enemigo literario a un cuerpo abyecto. Este gesto alcanzará su paroxismo en Céline, por ejemplo en « À l'agité du bocal » (1948), panfleto que el doctor Destouches le dedica a Sartre, quien lo había acusado de recibir dinero por parte los alemanes en un artículo de Les Temps modernes, el célebre " Portrait d'un antisémite ». En su respuesta, Céline compara a Sartre con una "ténia des étrons, faux têtard », que no puede ver claro, porque habita en su intestino : «Dans mon cul où il se trouve, on ne peut pas demander à J.-B. S.[Jean-Paul Sartre, llamado por Céline «Jean-Baptiste » Sartre] d'y voir bien clair, ni de s'exprimer nettement $»^{32}$.

La novela parece redireccionar a la denigración sobre el cuerpo del otro que ejerce el fascismo, volviéndola contra el propio fascismo. A esa lógica responde el "rapport » Laubreaux, una suerte de informe -inventado por Asís, obviamente- sobre la vida cotidiana bajo la ocupación que se concentra en los aspectos sexuales. El nombre no parece elegido al azar : Alain Laubreaux era uno de los redactores más virulentos de Je suis partout, no afectado según Rebatet por « le moindre débat de conscience » ${ }^{33}$, y se supone de hecho que habría jugado un rol importante en la detención del poeta resistente Desnos. Labreaux también es recordado por sus reseñas teatrales antisemitas y por las trompadas que recibió en público por parte del actor Jean Marais, escena esta que fue ficcionalizada libremente por Truffaut en Le dernier métro (1980), y que lo marca con esa cobardía física que para el narrador de Lesca... es propia de los « canallas ». Como si fuera una revancha del narrador -en este punto extrañanamente moral- contra el fascismo, el « rapport » de Laubreaux se convierte en una lectura humillante de la sexualidad de la Ocupación, que degrada a los colaboracionistas varones, a las "damas de orgasmo conflictivo " (Asís 2000 : 149) dispuestas a la collaboration horizontale, pero también a los invasores alemanes, eyaculadores precoces según el Laubreaux ficcional :

Con acierto, Laubreux consideraba, por último, que los camaradas no debían perdonarse el abandono de las excitadas mujeres a la precariedad sexual de los precoces oficiales alemanes. A su criterio, los boches carecían de estilo para apaciguar las sutilezas del erotismo activo de la estilista mujer francesa. Consignaba con insistencia, en su sarcástico " rapport », que no hacía concesiones a los dogmas firmes de Maurras al afirmar que los nazis acababan demasiado pronto. (Asís 2000 : 149)

30 En esta misma lógica « reventada » deben leerse las imágenes misóginas de las mujeres que aparecen en la novela, ninguna de las cuales responde al ideal de "mujer fascista » como ángel guardián del hogar del guerrero. Paradójicamente, la misoginia reventada del narrador desestabiliza los roles de género fuertemente jerárquicos y estratificados de la ideología de la "Révolution nationale », que se resumía en la divisa "Travail, famille, patrie » : nada subsiste en Lesca... de ese « eterno femenino » como organizador social que describiera Francine Muel-Dreyfus en Vichy et l'éternel féminin. Contribution à une sociologie politique de l'ordre des corps (1996). Si en las retóricas fascistas la prostituta es la contaminación que se opone a la mujer maternal que representa el cuerpo nacional y 
asegura su reproducción, la novela, por el contrario, se abstrae de este clivaje. El « crudismo » con el que se describe la sexualidad canalla se extiende a todas las mujeres, (y de hecho, la propia imagen de la prostituta se extiende a todos los hombres, dado que Lesca compara a los fascistas y a los intectuales precisamente con « putas » [Asís $2000: 40$ y 115]).

31 En la misma línea, el narrador hace una lectura «reventada » de la vida cultural de entreguerras, y convierte a la « rive gauche» historiada por Herbert Lottman (a quien cita explícitamente) en una suerte de "Dorado sexual», en donde evolucionan «los mejores novelistas [norte]americanos empeñados en la fornicación» (Asís $2000: 126$ ). También en el mismo tono, el narrador observa que los franceses inmersos «en el hartazgo moral de la guerra » se entregaban en los ' 30 « a la ceremonia del queso podrido y a la estimulación de sus mayoritarias mujeres que intensificaban -como erótica consecuencia de la falta de hombres - la vocación a acariciarse entre ellas » (Asís 2000 : 127). Se trata de una misoginia "crudista", que retoma un tópico decadentista, característico de la extrema derecha : los excesos de la cultura y la sexualidad, así como el replanteo de las relaciones de género patriarcales, llevan a la desmoralización militar y por tanto a la derrota. Pero a través de un corrimiento, este tópico es usado ahora en contra del fascismo. Porque si desde el machismo « crudista » rioplatense el ejercicio de la sexualidad masculina es un valor positivo, los «novelistas globalizados, que aspiraban sobre todo, a ponerla» (Asís 2000 : 127) -Henry Miller, por ejemplo- serán obviamente más dignos de simpatía que los fascistas « eyaculadores precoces » o « impotentes ».

32 Desde esta perspectiva «crudista » también se reseña le relación de Rebatet con su esposa Véronique («Colaborar con los alemanes podía ser más digno y enaltecedor que montársela, con el objetivo sano de no escuchar sus reproches » [Asís $2000: 150]$ ]). Y en el mismo tono se describe a las mujeres que « aguardan ansiosamente » en el Flore y en Les Deux Magots al invasor alemán (Asís 2000: 149); a las prostitutas de trottoir; a las intelectuales que desafían los estereotipos de género como Simone de Beauvoir (acusada por Drieu de "abnegada pederasta de ida y vuelta " [Asís 2000: 156]); o a Victoria Ocampo, dotada según el narrador de una «belleza utilitaria» (Asís 2000 : 73), esto es, apropiada para « deslizarse » en el mundo intelectual. La figura más parecida al ideal de matrona fascista, la esposa de Lesca, es mencionada por el indirecto libre del narrador con evidente desprecio :

Ella había sido la mujer ideal para una etapa considerable de su vida de luchador fascista. Le había resultado de espléndida utilidad, como hembra pasiva, con la ventaja incomparable de la seguridad. La sabía desmesuradamente silenciosa, agradecida y sumisa, sin reproches ni quejas y para todo servicio. Para el servicio higiénico de la cama, donde la criolla se abría para recibirlo y ocurría un polvo poco memorable. (Asís 2000 : 173)

Por lo demás, la candidata ideal a joven heroína fascista, Annie Jamet, recibe un tratamiento parecido: Drieu la describe como una "homosexual similar» a Brasillach, quien « la exhibía para simular su condición incuestionable de pederasta » (Asís 2000 : 77) y el narrador marca la distancia entre su muerte causada por " una estúpida peritonitis » y la muerte heroica buscada por los fascistas (Asís 2000: 82). En este cuadro, las prostitutas no ocupan un lugar excepcional ni alegórico : son apenas un emergente entre otros de un «reviente " general, o de una colaboración no ideológica, forzada por la necesidad. Así lo ilustra el caso de la prostituta Noelle, para quien « el polvo carecía de ideología » (Asís 2000 : 181). La cual por lo demás parece heredar este colaboracionismo forzado de su padre, un operario que nunca regresó de su trabajo voluntario en Alemania, 
y quien es definido como "Colaboracionista sólo por conveniencia y dinero, francos crocantes para la diaria baguette» (Asís 2000 : 197). Desde la perspectiva del narrador, será la misoginia exacerbada durante la épuration la que conviertirá a las mujeres en chivo expiatorio, haciéndolas el emblema del cuerpo nacional invadido, particularizando en ellas una colaboración que fue general. Serán los liberadores -descriptos por el ambiguo indirecto libre como "las huestes oportunamente resistentes", como los "repentinos partidarios de la purificación liberadora», a los que animaba «una noción autojustificatoria de la venganza » (Asís 2000 : 177)-, quienes harán del corte de cabellos al que acompañan "cinematográficas escupidas", de la tonte, "una especie de nueva estrella amarilla " (Asís 2000 : 81), situación que ha sido lúcidamente analizada, entre otros, por Enzo Traverso ${ }^{34}$.

34 La virilidad de Lesca sufre esta misma interpretación « reventada ». Hombre fuerte, representante de una América que, con su mejor fascismo, habría de regenerar a una Europa en decadencia, el «irreductible » termina apenas como un compadrito que, en buena tradición tanguera, le propina "tortazos circunstanciales» a una "putarraca de Avignon $»^{35}$. Más todavía, siendo un hombre ya maduro, y para peor, con problemas cardíacos, Lesca no responde al ideal fascista de la juventud : es un cuerpo enfermo. Su dominio se funda en una « carne » que no es la del cuerpo sacrificial del soldado, sino la del negocio agroexportador. La fuerza del «irreductible» no se origina en ninguna energía volcánica primordial, de esas que tanto conmovían al imaginario fascista, sino en ese « commerce de viandes froides » que según Bardamu, había tomado durante la Primer Guerra Mundial precisamente « les proportions d'une force de la nature $»^{36}$. El narrador lee entre líneas las fuentes colaboracionistas, y entiende que los elogios que recibía el Lesca histórico por parte de los fascistas se debían sobre todo a su poder económico ${ }^{37}$. El « irreductible " asisiano no es un hombre de acero, sino un " competente empresario » (Asís $2000: 28$ ) que « tiene la vaca atada " (Asís $2000: 41$ ), un « mercader de corned beef » (Asís 2000: 165), como dice Brasillach. Cliente habitual de las putas de trottoir, «braguetero rápido que soltaba con facilidad los francos » (Asís $2000: 175$ ), podríamos decir que paga una carne con otra. A través del dinero, entonces, Lesca construye su posición de varón preeminente, desde la cual desprecia la falta de virilidad de los petimetres fascistas, pero también su "idealismo", propio de "giles", "otarios" y « turritos ». Contra toda ficción del « idealismo fascista », lo « concreto », que es el juego político. La carne (que es dinero) contra la «idea ». (Y de paso, también, contra Victoria Ocampo : en uno de los asados organizados por Lesca en Auteuil, el Drieu ficcionalizado en la novela convierte, a través de un chiste equívoco, a la animadora de Sur en «carne argentina » [Asís $2000: 81$ ] ; un comentario que se aproxima al tono misógino usado para las mujeres en general y para las hermanas Ocampo en particular en el Journal 1939-1945 y que se aleja ciertamente del tono reconcentrado y por momentos lírico de la correspondencia con Victoria editada por Julien Hervier $^{38}$ ).

35 La carne, insumo simbólico del modelo agroexportador, como medio de elevación literaria y de «esnobeo » de los «románticos» fracasados como el "pederasta » Brasillach. Un instrumento para someter a los pretenciosos franceses, y para invertir, en la ignominia fascista, la dirección centro-periferia de los intercambios de la república mundial de la letras, verdadera fuente de ansiedad del esnobismo literario argentino. Y para permitirle a Lesca " esnobear ", incluso, en tanto ungido representante de la cultura francesa, a esos otros advenedizos, los invasores alemanes : 
Los predominantes incautos de la colaboración suponían, en su afán de venderse, que bastaba con obedecer a los alemanes. En cambio Lesca, excelente calculador asesorado por el inescrupuloso Claude [Maubourguet], prefería explotar el atroz complejo de inferioridad que los alemanes sentían hacia los franceses. En el específico plano cultural, los bárbaros -enseñaba Séneca- vivían siempre fascinados por aquello que amenazaban destruir. Como los bárbaros, los nazis temibles amenazaban con destruir aquello que los fascinaba. Un reclamo afectivo por ansias explícitas de aprobación cultural. Los bárbaros aspiraban al reconocimiento. Lo comprobaba en sus minuciosos y frecuentes diálogos con el embajador Otto Abetz. $\mathrm{O}$ con el astuto propagandista Karl Epting, y hasta con el misterioso Bern[h]ard Payr, especialista que se encargaba de literatura y comunicación, o con cualquier oficial de maneras caricaturescas. Sentía que el alemán deseaba que el francés creyera que había venido a ocuparlo y vencerlo, pero para salvarlo. Aspiraba a ser culturalmente aceptado, reconocido por el vencido. Tierna y violentamente, el alemán sensible reclamaba aceptación. Suplicaba ser considerado como otro francés, una idea romántica que se desprendía del texto de Vercors. Y el argentino doblemente trasplantado, que conocía como nadie la articulación de las imposturas, no les iba a ceder fácilmente el privilegio de considerarlos. (Asís 2000 : 162)

\section{Ni droite ni gauche : indeterminación formal y « tercera posición »}

36 La novela Lesca... es un texto organizado en torno a la indeterminación, a través de recursos formales tales como el indirecto libre, la confusión entre relato ficcional y factual, el montaje, la saturación de referencias, el paralelismo, el anacronismo. Ha dicho Josefina Ludmer :

Lesca es un libro inquietante, sobre todo por la posición de la enunciación : el discurso del narrador hace un uso particular del indirecto libre. Por momentos " habla » el fascista y en la voz de Lesca aparece el mal; sin embargo, no es «La refalosa » de Ascasubi ni «Deutsches Requiem » de Borges porque no parece haber voz del bien. Tiene una doble posición de enunciación y traza un movimiento oscilante en el tono de las palabras : a los fascistas los llama « los patriotas », a uno «otro genio », pero también aparecen como «los canallas» o «el petimetre». Ironiza sobre el fascismo y también sobre sus enemigos : no está con ninguno de los dos, se pone en los dos y en ninguno, se pone en cada uno con la perspectiva enemiga del otro. Hay dos demonios o dos otarios necesarios el uno para el otro, o no hay ningún demonio (se ríe del fascista Lugones, un « suicida anunciado » que ni siquiera era antisemita). Borra fronteras o desdiferencia entre bien y mal y entre realidad y ficción. ${ }^{39}$

Este borramiento de las fronteras entre novela y ensayo obliga permanentemente al lector a preguntarse si lo que se está diciendo "es cierto ", y si no lo es, cuánto hay de invención literaria y cuánto de « dato histórico », y si se asume que podría haber un dato histórico « cierto », qué hace exactamente la ficción con ese « dato ». Por ejemplo, cuando el narrador se refiere a un encuentro entre el historiador Jacques Bainville y Leopoldo Lugones, aclarando que no fue registrado por el biógrafo lugoniano Alberto A. Conil Paz (Asís 2000 : 79-80), o cuando describe una entrevista entre Lesca y Victoria Ocampo, diciendo que el evento no fue registrado ni por las biógrafas Laura Ayerza de Castilho y Odile Felgine, ni por Beatriz Sarlo (Asís 2000 : 160). En estos casos, se marca el alejamiento del registro de la ficción realista y parece haber un acercamiento al género de la biografía literaria o el ensayo crítico. Pero a la vez este acercamiento también es puesto en duda cuando se dice que la anécdota no está avalada por las fuentes históricas. La anécdota, ni 
ficción realista ni registro histórico, queda en una especie de indeterminación, entre el relato ficcional y factual: se convierte en una marca de ambigüedad genérica y de montaje.

38 El montaje, por lo demás, funciona en varios niveles, creando confusiones entre diversos universos referenciales. Entre Argentina y Francia, lingüísticamente, a través de la exportación al contexto francés de una suerte de lunfardo político argentino (o más bien asisiano, dado que muchas expresiones pueden encontarse en las actuales crónicas de Asís sobre política argentina) : "Cincuenta días de detención; una 'cana'que Lesca debería facturar con intereses propagandísticos» (Asís 2000 : 137) ; «trepar " (Asís 2000 : 141); « comprarse la pelea ( (Asís $2000: 12$ ) ; «Copar las paradas »(Asís $2000: 62)$; « quedarse con un vuelto »(Asís $2000: 61-2$ ) ; « caramelo de madera » (Asís $2000: 207$ ), término del argot político para referirse a un beneficio que se le da a un aliado con el objeto de mantenerlo medianamente conforme, pero que es muy inferior al don realmente esperado ; « ser un perejil » (Asís $2000: 61$ ), vocablo que refiere a los militantes de menor rango de las organizaciones políticas de la izquierda de los '70.

39 Entre América Latina y Europa, cuando el narrador habla del auge de la literatura antisemita como un «boom » (Asís 2000 : 157) y menciona el « realismo mágico » (Asís 2000 : 107), en una obvia referencia al « boom latinoamericano».

40 Entre diferentes tiempos de la historia, cuando el narrador, anacrónicamente, le hace decir a Lesca una frase «vandorista » a la que volveremos más abajo: «Para salvar a Maurras hay que estar contra Maurras » (Asís 2000 : 146).

41 Entre izquierda y derecha, cuando se presenta a Brasillach como un escritor « comprometido » superior a Zola (Asís 2000 : 12), o cuando se menciona a Stalin como « el humanista infatigable aún no debidamente reconocido por los canallas » (Asís 2000 : 32).

42 A la desestabilización que produce el montaje, hay que sumar las referencias intertextuales a las otras obras de Asís, ambientadas todas en las últimas décadas del siglo $\mathrm{XX}$ y que aluden de forma más o menos directa a la política argentina. De este modo, la idea según la cual Lugones llevó a adelante una revolución " puramente literaria » remite claramente a la evaluación que Asís hace de la militancia revolucionaria argentina de los '70. Y en la misma línea Asís ha sugerido en la entrevista de $E l$ ojo mocho que el Je suis partout ficcionalizado en Lesca... es la versión nazi del Clarín descripto en Diario de la Argentina (1984), con lo cual Lesca sería una suerte de avatar de Bagnatto, el doble literario del CEO de Clarín, Magnetto ${ }^{40}$. Cadena asociativa que sería continuada años después por algunos lectores con la boutade « Garquín es Je chie partout » (recuérdese que el poeta resistente Robert Desnos había rebautizado «Je chie partout » a Je suis partout).

Otro recurso formal que acentúa la indeterminación es el paralelismo. De allí el recurso a las Vidas paralelas de Plutarco, obra que se menciona más de una vez, aunque naturalmente sin su carga moralizadora : «Mussolini y Lugones podrían haber inspirado a un Plutarco contemporáneo " (Asís 2000: 66-7), dice el narrador. La apelación anacrónica al ejercicio retórico de la synkrisis plutarquiana es otra parodia del discurso historiador. Citemos en ese mismo espíritu anacrónico al venerable Fontanier: «Le Parallèle consiste dans deux descriptions, ou consécutives ou mélangées, par lesquelles on rapproche l'un de l'autre, sous leurs rapports physiques ou moraux, deux objets dont on veut montrer la ressemblance ou la différence $»^{41}$. Identidad o diferencia, aproximación o separación son los resultados posibles de la puesta en contigüidad. o puede darse que 
ambos resultados sean simultáneos : Lugones es como Mussolini (porque de Lugones ya no importa su valor literario, sino su fascismo), y Lugones no es como Mussolini (porque Lugones es apenas un fascista sin importancia, y la comparación con Mussolini demuestra, por la vía del ridículo, su escaso valor, de apenas unos pocos « capdevilas ", así como la tontería de Lesca, quien enuncia la comparación).

44 La similitud y disimilitud simultáneas ponen en crisis el sistema de delimitaciones políticas, literarios y nacionales : ¿qué equivale a qué? ¿todo es, en algún punto, lo mismo? Si un "yunque» vale dos «capdevilas» ¿cuántos «lugones» vale un « mussolini »? ¿cuántos « lescas» contantes y sonantes una «victoria ocampo »? ¿y a cuánto cotiza el « sartre »?

45 El montaje sugiere series, bloques de equivalencias; pero a la vez separaciones, si se interpreta a la serie como la aproximación irónica entre elementos heterogéneos. Por ejemplo :

« Hitler era en adelante el poder. Era la única y conveniente realidad. Enfrentarlo -

afirmaba Lesca- era una pelotudez. Proclamaba :

-La unica verdad es la realidad» (Asís $2000: 145$ )

46 Al hacer decir a Lesca antes que Perón la famosa frase de Perón ¿se dice que Lesca anticipa a Perón, que Lesca tiene algo de Perón, que Perón tiene algo de Lesca ? ¿O más bien se ironiza contra el tópico antiperonista del «fascismo de Perón»? Algo similar sucede cuando Lesca dice : " Para salvar a Maurras, hay que estar contra Maurras » (Asís 2000 : 146), en el contexto de la ruptura motivada por las diferentes posiciones frente a la invasión nazi. Maurras, colaboracionista y antisemita, era un entusiasta admirador de la «divine surprise» de la "Révolution nationale» de Pétain, pero a causa de la germanofobia de su nacionalismo integral habría mostrado, al contrario que Lesca, un mínimo reparo contra la ocupación nazi. Ahora bien, para dramatizar este conflicto se cita aquí una frase que el sindicalista Augusto Timoteo Vandor habría dicho en 1965 en medio de su puja política con el líder en el exilio : «Para salvar a Perón hay que estar contra Perón ». ¿Qué significa esta aproximación entre Maurras y Perón? ¿Sería Lesca «el Vandor» de Maurras? (Si así fuera, los nazis serían los liberales argentinos que proscribieron al peronismo...). En el mismo sentido, la afirmación de que Lesca se impone gracias a su « prepotencia de trabajo » (Asís 2000 : 123), una cita de las célebres «Palabras de autor» de Los lanzallamas (1931) de Arlt, lleva a pensar en la relación entre Arlt y el fascismo europeo, una línea explorada por José Amícola en Astrología y fascismo en la obra de Arlt (1994[1984]).

47 Indirecto libre, ambigüedad genérica, anacronismo, montaje, saturación de contraseñas políticas, de referencias intertextuales, de nombres propios. Una indeterminación que obliga a detenerse, como ante un rumor conspirativo, en cada referencia : las conexiones que existen, las que se sugieren, las que no existen pero podrían sugerirse, las que tras haber sido sugeridas hay que descartar como irónicas «chicanas». De allí la dificultad para decodificar la verdadera distancia que el narrador tiene con la voz de los " canallas », para calibrar cuánto hay de maledicencia satírica puramente gratuita, cuánto de parodia del odio fascista, cuánto de absorción del odio fascista por parte del odio « reventado », cuánto de ajuste de cuentas peronista contra el liberalismo argentino. El efecto que producen estos procedimientos formales de indeterminación se aprecia claramente en la descripción de Victoria Ocampo :

La Ocampo hacía con la cultura lo que Lesca intentaba hacer con el fascismo. Ambos

especulaban con las ideas que tenían los otros desgraciados acerca del imán de sus 
fortunas. Para Lesca ella era otra argentina viajera, de las que cruzaba el Atlántico como si fuera la Avenida Alvear. (..) Victoria pertenecía a la generación de extravagantes aristócratas encadenados en una severa declinación económica que reflejaba su impotencia política. (..) Victoria se destacaba por sus positivas inquietudes culturales. Por su inteligencia para escoger, y por su belleza utilitaria, aliada a una fortuna que se diluía como agua en la arena. Solía lucirse por la coacción tentadora de las invitaciones que formulaba a los intelectuales aún baratos y accesibles, para disertar y exhibirse en el país imaginario del sur, y pernoctar en una casona magistral de San Isidro, próxima de un río de la Plata que todavía servía hasta para bañarse y leer poemas erróneos en la playa. Victoria dirigía, en aquellos parajes culturalmente colonizados, una revista enaltecedora, espiritualmente diferente de Je suis partout. El engendro se titulaba Sur, un medio tan sofisticado como necesario, que se proponía como un rejunte elemental de colaboraciones traducidas, de artículos escritos por los pensadores nativos del lugar que se enorgullecían por figurar junto a los superiores extranjeros, y con textos redactados en un español que parecía traducido de un francés declinante que aún mantenía su transitoria vigencia. Merced al despiadado provincialismo cultural, la publicación sería presentada, sin mayor rubor, y durante décadas, como un ejemplo para mitificar, esbozos de una memoria honorable para la engañosa posteridad.

En la casona de San Isidro, junto al río próximamente inútil y los mosquitos que se multiplicaban, la reina Victoria aguardaba, para proyectarse, a los padecidos intelectuales europeos de exportación. Llegaban sus barcos, como las putas polacas que sigilosamente importaban los tenebrosos judíos de la Zwi Migdal. Los escribas, con sus intensos prestigios vulnerables, se animaban a la aventura de cruzar los mares del sur, para seguir el camino fatigado por Paul Groussac, un desconocido fundacional.

(..)

La gran mayoría del lote de viajeros angustiados procedía de París, donde la Ocampo sabía estremecer el espeso ambiente de entreguerras. Utilizaba el cencerro seductor de sus monedas cautivantes, que fácilmente penetraban las entretelas de una Europa miserable, de intelecto congénito y apetito superior. (Asís 2000 : 73-5)

El indirecto libre reproduce los tópicos del pensamiento fascista de Lesca ( tenebrosos judíos", el francés como lengua en declinación, el triunfo del dinero, la misoginia, la referencia a la proliferación de los insectos -en esta caso mosquitos-, las críticas antiliberales por derecha). Pero también se incluye brevemente la perspectiva de Victoria Ocampo (solo desde su punto de vista la revista Sur puede considerarse "enaltecedora»). Asimismo, la saturación de referencias dispara analogias $\mathrm{y}$ connotaciones que el lector puede, o no, decodificar. Así, pues, la mención a la organización de «trata de blancas» Zwi Migdal, puede evocar los siguientes elementos : el modelo agroexportador (la prostitución es un "comercio de carne", según la frase hecha) ; la propia idea de Lesca de que los intelectuales y los fascistas son como putas; la xenofobia antisemita antiinmigratoria argentina (recordemos que el libro sobre la Zwi Migdal publicado por el comisario Julio Alsogaray en 1933, Trilogía de la trata de blancas, tiene largos pasajes antijudíos); el imaginario arltiano (Haffner, el rufián meláncolico de Los siete locos, estaría inspirado en Noé Trauman, uno de los cabecillas de la Zwi Migdal); el imaginario prostibulario del tango, también presente en la novela, desde Noelle hasta el « Tango del nacionalismo » del último capítulo ; Albert Londres, quien escribió Le chemin de Buenos Aires: la traite de blanches (1927), donde se analizan las relaciones francoargentinas sub specie prostitutae (vel proxenetae); en fin, el desafío de los roles genéricos establecidos de Victoria Ocampo, quien -según esta metáfora enunciada por un indirecto libre cercano a la voz de Lesca- no es prostituida, sino prostituyente (y por tanto viril), lo 
cual puede entenderse como una forma oblicua de expresar reconocimiento por parte del «irreductible».

Por lo demás, si Lesca esnobea "por derecha » las pretensiones culturales de Victoria Ocampo, lo hace utilizando tópicos de la izquierda nacional de los '60 (« aquellos parajes culturalmente colonizados »). ¿Sugiere aquí Asís un parentesco entre fascismo e izquierda nacional, o se trata apenas de una aproximación circunstancial para una crítica a lo Hernández Arregui de la revista Sur, clásica en el campo cultural peronista? Quizá sea imposible decodificarlo. En todo caso, habría que decir que si, a causa del peso de la figura pública de Asís, Lesca... se leyó "solamente» como un intento menemista de "desdiferenciación" entre izquierda y derecha, como una forma de la memoria neoliberal (Ludmer) ${ }^{42}$, lo cierto es que esa indeterminación ideológica es más compleja.

50 Por un lado porque -como veremos- la entrada en escena de Perón (el «metalúrgico », o "fundidor », como diría Leopoldo Marechal en El banquete de Severo Arcángelo [1965]) provocará una cierta suspensión de la ironía (movimiento que es indicio, por lo demás, de un juego algo discordante entre la indeterminación y afirmación, propio de los « deslizamientos » del « personaje Asís »).

51 Por otro lado porque la indeterminación ideológica de la novela, que responde a un laborioso dispositivo formal, tiene otro efecto. Permite captar esa posición ni droite ni gauche, que caracteriza a los «non conformistes » de los años '30, según llama Jean-Louis Loubet del Bayle ${ }^{43}$ a toda una serie de intelectuales, entre los que se contaban por ejemplo Maurice Blanchot, Robert Brasillach, Thierry Maulnier, Emmanuel Mounier, Charles Mauban o Robert Aron, que participaban en revistas como Réaction pour l'ordre (1930-1932), L'ordre nouveau (1933-1938), Esprit (fundada en 1932), Civilisation (1938-1939) o Plans (1931-1933). Intelectuales que tendrían trayectorias diversas : algunos adherirían al fascismo; otros tras una breve adhesión a la "Révolution nationale» de Pétain, se pasarían a la resistencia ; muchos optarían por diversas formas de « tercera posición », ya sea ni comunista ni fascista, ya sea ni liberal ni comunista, como el mencionado Mounier, cuyo " personnalisme » tuvo tanta repercusión en Sur.

52 La exacerbación de la perspectiva ni droite ni gauche que explota Asís le permite al narrador comparar a Je suis partout con Sur y a Lesca con Ocampo. Lo interesante es que, saliendo del plano ficcional, la comparación entre Lesca y Ocampo ofrece aristas llamativas : ¿no participó acaso activamente el Lesca histórico en el que se inspiró Asís, en el Bulletin de la Bibliothèque américaine (1910-1916), el Bulletin de l'Amérique latine (1916-1921) y la Revue de l'Amérique latine (1922-1932) ? Editadas bajo el patronazgo del Groupement des universités et des grandes écoles de France pour les relations avec l'Amérique latine, estas revistas fueron sumamente importantes para el hispanismo francés y la circulación de ideas y textos entre Latinoamérica y Francia ${ }^{44}$. Con cierta simpatía por las ideas de Maurras, estaban estructuradas alrededor de la idea de «latinidad» (una latinidad que también incluía a Canadá, como documenta un trabajo de Michel Lacroix ${ }^{45}$ ). Proyectos estos que participan también del flujo de intercambios intelectuales entre Francia y América Latina y en los cuales ocupa un lugar central la traducción. Más aún, encontramos en los bulletins y en la revue colaboraciones de autores que estaban ligados a la revista Sur: Jean Cassou, José Ortega y Gasset, Valery Larbaud, Pedro Enríquez Ureña y Gabriela Mistral, entre otros.

53 Así las cosas, el montaje de tiempos e ideologías de Lesca... -un verdadero "casino ideológico »- produce un desconcierto similar al del clima ni droite ni gauche que Zeev 
Sternhell y otros han descrito en sus investigaciones, y que de hecho, solemos experimentar cada vez que nos acercamos a la literatura de los años ' 30 y '40. Piénsese, por ejemplo, en los inquietantes puntos de contacto con el fascismo de la revista Acéphale (1936-1939), animada por Pierre Klossowski, Roger Caillois y Georges Bataille, entre otros ; en las afinidades e intercambios entre diversas vanguardias estéticas y el soreliano Georges Valois, fundador del primer partido fascista francés, Le Faisceau, y director de la publicación de extrema derecha Cahiers des états generaux (1923-1925), cercana a la Action Française ${ }^{46}$; en Drieu la Rochelle, quien supone que la Unión Soviética ganará finalmente el combate contra el liberalismo que ha emprendido el fascismo, y prefiere a Stalin antes que a un Hitler al que encuentra demasiado débil : «Staline est de droit divin, de droit populaire absolu et ses hommes sont des aristocrates comme il n'y a en avait pas eu depuis des siècles (...) Je mourrai avec une joie sauvage à l'idée que Staline sera le maître du monde. Enfin un maître. $»^{47}$ dice en su Journal.

54 Ahora bien : más allá de esta indeterminación general, surge, hacia las últimas páginas de la novela, como centro reorganizador de las diferencias, la figura de Perón : « Pero Perón no era Hitler ni Braden era Churchill, y lo más significativo aún, la Argentina podía admitir una cierta jactancia europea pero su realidad era otra » (Asís $2000: 215$ ). Más aún, esta demarcación viene acompañada de un cambio de tono ; por primera en la novela vez algunas líneas que describen un proceso político parecen no ser irónicas :

En materia de reivindicaciones sociales Perón había avanzado mucho más de lo que se hubieran atrevido los propios comunistas. Desde la insignificancia administrativa de una iniciática Secretaria de Trabajo y Previsión, con el despliegue de auténticas reformas transformadoras que le permitían al trabajador aproximarse a una cierta idea de dignidad, ante el asombro espantado de una derecha inculta que entendía nada del juego y se hacía gárgaras de reacción mientras despotricaba, con perplejidad y estupor, acerca de los actos de la demagogia populista (Asís $2000: 214$ )

Según el narrador, Perón organiza el clivaje en el campo nacionalista entre los « atorrantes » (los nacionalistas populistas democráticos, « populacheros » $\mathrm{y}$ « forjistas ») y los «canallas» fascistas, tratados ahora como «pintoresquistas que defendían con autencidad posiciones demenciales» (Asís 2000 : 209). A diferencia por ejemplo de lo que sucede en La matriz del infierno (1997) de Marcos Aguinis, donde Perón es un aprendiz de fascista que visita la embajada argentina en Alemania y se lee, por tanto, al peronismo a partir del fascismo, reproduciéndose así cierta doxa liberal, en Lesca... el fascismo se lee a partir del peronismo. Esta operación, por lo demás ya en cierto sentido anticipada por la colonización léxica del fascismo por parte del argot político argentino, culmina en una lectura «irónica » del fascismo por parte del peronismo, fundada, desde la óptica del narrador, más en el descrédito político que en consideraciones morales. Perón encarna la forma exitosa del nacionalismo, mientras que los fascistas representan la forma fracasada del nacionalismo y devienen, por tanto, acreedores a los denigratorios « caramelos de madera » :

A los nacionalistas de su estirpe, sospechaba, Perón los iba a traicionar. Los iba a usar y tirar después por la ventana. Los otarios servirían como ideólogos iniciales y activos pero descartables. (...) Ocurría que Perón era demasiado inteligente para tomarlos en serio y hacerles medianamente caso. $\mathrm{Y}$ se burlaba, en trascendente secreto, de los totalitarios incautos del catolicismo nacionalista, los maurrasianos desconcertados que se habían equivocado de continente, fascistas tristes y resentidos (...) Perón era demasiado astuto para arriesgarse a mantenerlos como enemigos (...) Debía mantenerlos entretenidos, pero lejos de los ámbitos de decisiones.

(...) 
Perón, a su juicio, era demasiado populachero, y abrumaba a los nacionalistas hasta la perplejidad. Aplacaba a los tradicionales adoradores de las elites con la presencia ofensiva de los mayoritarios desposeídos. Perón les tiraba todos los días con pobres (..) Los doblegaba [a los nacionalistas] con la palabra envolvente, los atormentaba hasta el ridículo con la ironía y los reducía con la potencialidad gestual de sus celebraciones teatrales. A pesar de tantos atributos que deberían conformar al riguroso imaginario previo, era indudable que Perón distaba de ser el hombre que los nacionalistas aguardaban. Encaraba un proyecto diferente y no le importaba defraudarlos. (Asís $2000: 207-8)^{48}$

Perón construye el lugar de su « enunciación política » -para hablar como Verón y Sigal en Perón o muerte. Los fundamentos discursivos del fenómeno peronista (2003[1986])-, diferenciándose del liberalismo y del comunismo, pero también del fascismo. Perón construye teatralmente su propia singularidad, esto es, su propia interpretación de la «tercera posición». En tal cambio de condiciones políticas, Lesca, de vuelta en la Argentina, le provoca a Perón «una predominante indiferencia equivalente al desinterés " (Asís 2000: 200). Lesca ya no puede sostener un lugar dominante de enunciación, no logra obtener su « reconocimiento de especialista en las características diferenciadoras de los distintos procesos continentales" (Asís 2000: 200). La nueva situación hace evaporar el capital simbólico del « irreductible » :

Para colmo, tampoco funcionaba la unificadora cruzada del antisemitismo. Una pasión trágicamente pintoresca que había movilizado las mejores energías de los 'nacionalistas europeizantes'. Para los nuevos nacionalistas que irrumpían bajo el paraguas del peronismo, el antisemitismo resultaba un acto irrelevante y penoso.

-Pero lo más grave de todo, compañero, es que ser antisemita es una estupidez.

[Lesca] Debió soportar, en su decadencia, que así le hablara un mocoso impertinente, con sospechosa cara de rusito. Se hacía llamar Abelardo, tenía pecas y lo había escuchado pontificar a Lesca en el café Tortoni. Un colorado irónico (..)

(Asís $2000: 211)^{49}$

57 Ahora, el peronismo "atorrante ", a partir de un nuevo sentido de las distinciones culturales y políticas, por boca de «El colorado » Ramos, «esnobea » al antisemitismo fascista, « canalla ».

\section{La república reventada de las letras}

58 La novela Lesca... -en este punto comparable a La literatura nazi en América (1996) del escritor chileno Roberto Bolaño- se distancia de un tono extendido para tratar el fascismo en la literatura argentina: el de la solemnidad y la interrogación filosófica, marcas constituyentes de «Deutsches requiem» (1946) de Borges. Este tono elevado puede encontrarse, por ejemplo, en las obras de dos escritores adscriptos a posiciones ideológicas opuestas, José Pablo Feinmann (peronista de izquierda) y Abel Posse (liberal conservador). En diversos textos ficcionales y ensayísticos, ambos interrogan a la cultura alemana del siglo XX en general, y a Heidegger en particular, como expresiones de una gran encrucijada histórico-filosófica. En tres novelas que pueden leerse de forma paralela, Los demonios ocultos (1987) y El viajero de Agartha (1989) de Abel Posse, y La sombra de Heidegger (2005), de José Pablo Feinmann, un personaje afectivamente comprometido con el pasado, el hijo de un nazi fascista, representante de la posteridad, debe hacer un balance de la historia, desde una perspectiva que podría acercarse, si se quiere, a la de las ficciones autobiográficas de Patrick Modiano. 
59 Ahora bien, en el caso particular de los textos de Abel Posse, reproductor acrítico de ese «mito Jünger» al que ya hemos aludido, la elevación del tono adquiere dimensiones hiperbólicas. Tras reivindicar a los intelectuales de la "revolución conservadora" alemana, Posse, en su ensayo «Ernst Jünger, el eterno guerrero » ${ }^{50}$, escribe frases como esta :

Su diario parisino [el de Jünger] está determinado por el mismo esfuerzo : hacer prevalecer lo humano sobre el horror y la humillación de la ocupación. Sólo una civilización como las de los franceses puede comprender el juego : le permiten [a Jünger !] asistir de uniforme a reuniones con Picasso, Colette, Montherlant, Céline, Cocteau, Gide y el grupo de críticos de la Nouvelle Revue [Française]. ${ }^{51}$

60 Semejante lectura, según la cual la vida cultural bajo el dominio del Propaganda Abteilung de la Wehrmacht, el Einsatzstab Rosenberg y el Instituto alemán de Karl Epting, es un «juego » que goza de la comprensión de la « civilización » francesa, según la cual los franceses «le permiten» a Jünger asistir de uniforme a las reuniones (como si hubieran tenido margen de elección), y según la cual el « grupo de críticos » de la NRF (en ese entonces dirigida por el colaboracionista Drieu) representa de forma neutra a la cultura francesa, es ciertamente llamativa. Hoy solo podríamos encontrarla en las páginas, tan afectas al kitsch wagneriano-jüngeriano-spengleriano, de revistas de extrema derecha como Krisis o Nouvelle école, dirigidas por el filósofo « neopagano » Alain de Benoist.

61 Senkman y Sosnowski han señalado la ambigua fascinación de Posse por ciertos aspectos del « pensamiento » nazi, en particular por el esoterismo ${ }^{52}$. En cualquier caso, su lectura mítica de la cultura alemana -cuyo punto más alto es la rememoración del encuentro con un Heidegger ataviado de campesino en la Selva Negra- parece más bien deberse a la sobredeterminación del lugar institucional y social que ocupa como escritor y diplomático de una nación/cultura periférica. En este sentido, Posse reproduce ante la nación/cultura central los gestos de subalternidad que tan bien describe Pascale Casanova en la République mondiale des lettres (1999). La figura del « diplomático escritor », de larga tradición en la literatura latinoamericana (Pablo Neruda, Octavio Paz, Sergio Pitol), une preocupaciones « literarias » $\mathrm{y}$ « nacionales ». Expresa un cosmopolitismo periférico, cuya gran ansiedad es la superación del « atraso » local, la integración al tiempo « universal », siempre evanescente, de la modernidad cultural. Podría establecerse toda una tópica de la escritura de los escritores diplomáticos latinoamericanos : « extrañamiento » frente a la propia cultura ; «admiración" por la cultura central ; "deseo de incorporación al diálogo " de las culturas; "enriquecimiento» de la propia diferencia a partir de la confrontación con la cultura central ; «celebración » del encuentro (esto es, de la supuesta ruptura de la asimetría) entre las culturas ; "meditación » acerca de qué manifestaciones culturales representan mejor « ante el mundo » la propia literatura. El viaje diplomático le permitiría al viajero institucional medir la distancia entre lo local y lo universal, y desde esa posición juzgar la situación de la cultura y la literatura nacionales. El viajero podrá seleccionar, dado que se ha vuelto « universal »-precisamente como Paz, el «mexicano universal»- qué textos son la suficientemente «representativos», y merecen, por tanto, formar parte del canon de la literatura mundial (pensemos, sin ir más lejos, en la lista de textos « argentinos y rioplatenses » incluidos por Posse en su Biblioteca esencial : 101 libros fundamentales de la literatura mundial [1991]).

62 Significativamente, nada de esto se registra en la escritura de Asís -quien recordémoslo, también fue diplomático, o para decirlo más correctamente, si nos basamos en sus 
Memorias tergiversadas (2017), vivió de la diplomacia. Mucho menos en Lesca..., donde París es la capital de la república internacional de las letras fascistas, o el lugar de origen de modas progresistas que para el narrador son igualmente dudosas, en la medida en que legitiman la violencia de los regímenes comunistas (recordemos que en la entrevista de $\mathrm{El}$ ojo mocho Asís menciona la lectura de Le livre noir du communisme [1997], investigación de historiadores del CNRS sobre los crímenes del socialismo real, que iba en la misma línea de Le passé d'une illusion de François Furet). Asimismo, las instituciones culturales y diplomáticas que gestionan los intercambios culturales internacionales y que son un engranaje nada desdeñable de esa "fábrica de la universalidad» a la que se refiere Casanova, están abundamentemente satirizadas en Excelencias de la nada (2001) y Casa casta (2012), textos que ficcionalizan la experiencia diplomática de Asís como embajador ante la UNESCO y en Portugal.

63 Lesca... se distingue cortocircuitando la relación, central para cualquier escritor argentino, con Francia y con la cultura francesa. Lesca... pone a competir con la « embajadora cultural» liberal y canónica, Victoria Ocampo, un «embajador cultural fascista ». Desde esta perspectiva, los intercambios literarios de la « república reventada de las letras » no son la «producción de lo universal » que describe Casanova e incluso pueden redundar en la producción de una cultura para el exterminio, para el mal. Decir que la Argentina del '30 fue fascista, opresiva o « canalla » no es ciertamente nuevo en la literatura nacional -ahí está la denominación "década infame»-: lo notable y desestabilizador para la literatura argentina es situar a la referencia francesa en sincronía con ese movimiento. Como en una suerte de descentramiento lumpen de la república universal de las letras, la escritura de Asís pone en cuestión las referencias fundamentales de los intercambios desiguales entre Argentina y Francia - entre ellas el antifascismo de la francofilia argentina. Este ataque a la cultura francesa quizas explique que Lesca no haya sido traducida al francés. Por lo demás, no es un gesto de mucho tacto, en términos de diplomacia cultural, afirmar que París es la capital del fascismo mundial, que « las damas de orgasmo conflictivo » esperaban la seducción de los ocupantes nazis, o que la épuration fue una farsa. Se trata de temas obviamente sensibles para una Francia que tramita, como dice Henry Rousso, su « síndrome de Vichy ». Para medir la delicadeza del tema, recuérdese solamente la controversia que suscitó la tesis de Zeev Sternhell acerca del origen francés del fascismo, con acaloradas intervenciones de Michel Winock y Serge Berstein, entre otros ${ }^{53}$.

\section{Conclusiones : sic transit gloria " dandi »}

64 Este replanteo de la relación con Francia, meca de todos los esnobismos literarios argentinos, instala a la novela en un lugar ciertamente singular. Si el personaje Lesca « esnobea » a los fascistas y a los liberales, el « personaje Asís », con esta novela ni droite ni gauche -una novela que por lo demás exhibe un hábil manejo de las fuentes francesas-, « esnobea » a los lectores argentinos bienpensantes, lectores en general francófilos, que suelen identificar al mundo intelectual francés con la cultura del «progresismo » o la "modernidad estética», sin detenerse demasiado en la significativa contribución francesa al fascismo de entreguerras.

65 Lugar singular, el de la novela Lesca..., que se integra a la estrategia de autofiguración como escritor « dandi » o «maldito » del " personaje Asís ». Autofiguración -o " política de la pose ", para hablar como Sylvia Molloy- que, como en todo escritor, se construye 
tanto dentro de la obra como fuera de ella. En zonas separadas, las puramente literarias (la « novela », « el cuento ») o las puramente sociales (la " entrevista », « el tweet »); pero también en zonas limítrofes (en autobiografías como Memorias tergiversadas [2017], en las dedicatorias, en las solapas, contratapas y demás paratextos de los libros). Autofiguración, autobiografía y ficción forman parte de un mismo movimiento : «Uno cuando pone la palabra 'yo', ya casi miente ${ }^{54}$ dice Asís en la entrevista de El ojo mocho. No es posible, por tanto, leer « la ficción de Asís » más allá de la construcción pública, poniendo entre paréntesis el " personaje », como pretenden las lecturas académicas que reivindican la pura autonomía (lecturas en general elogiosas, que destacan la « cualidad literaria de la obra »); pero tampoco se puede identificar sin más a la obra con el autor, como suelen hacer las lecturas impugnadoras de la calidad literaria (tal el caso, por ejemplo, de una reseña de Tomás Abraham sobre Lesca..., donde se identifica, para descalificar a la obra, autor y personaje $\mathrm{e}^{55}$ ). La aufiguración se contruye en diversos planos (la ficción, la autobiografía, las intervenciones públicas) que intercambian tópicos y núcleos narrativos, sin que pueda establecerse, no obstante, una equivalencia entre tales planos. Muchos temas de Lesca... también aparecen en otras "ficciones de Asís ». Por ejemplo, el uso de la degradación sexual a los efectos de afirmar la propia posición dentro del campo literario se da en Flores robadas en los jardines de Quilmes, en la escena en la que se describe el « pajarillo inolvidable de Borges, en realidad un pájaro pálido, rugoso, breve $\mathrm{y}$ tal vez muy manoseado, desusado $»^{56} \mathrm{y}$ en Memorias tergiversadas, cuando el " yo" menciona a la « canallada literaria. Donde cualquier boludo, de los que cogen una vez por mes con la luz apagada y en pijama, quiere aparecer como el escritor maldito. Con la mirada desafiante y activa, para los suplementos culturales. $»^{57}$.

66 La singularidad de Lesca... debe contextualizarse, entonces, en esa " ficción de Asís ", que es a la vez política y literaria, que determina toda una serie de opciones, en tensión con el campo literario argentino, que ya han sido comentadas por Burgos, Parchuc y Drucaroff, entre otros críticos. Frente al liberalismo, el peronismo ; frente a la alta cultura, el mundo plebeyo; frente a los críticos universitarios, los lectores de best-seller; frente a la consagración académica, la promoción mediática; frente a la izquierda, el neoliberalismo; frente a la utopía colectiva, el pragmatismo individualista; frente al " setentismo ", el "noventismo »; frente al mundo del prestigio literario, el mundo del dinero y el poder real. La literatura (o el uso de la palabra en sentido amplio, que Asís suele definir como "vender humo ») como una forma de ascenso social, que se opone a la búsqueda de autonomía de los grandes mecenas como Victoria Ocampo (que invierten capital económico en lugar de obtenerlo), al ideal de investigación desinteresada del cursus honorum académico, y a la búsqueda de capital exclusivamente simbólico de los escritores « serios ». En las ficciones de Asís, el ascetismo artístico, la autonomía literaria, es impotencia sexual, tal como se advierte en el fragmento sobre Borges que recién hemos comentado: es la revancha imaginaria, more asisiano, de la clase baja contra la alta cultura. Revancha que es paródicamente ficcionalizada en una escena de Dulces otoñales en la que Rodolfo, alter ego del " personaje Asís », convertido ahora en un dandi " parisino », « rico » « refinado », le explica a su amante, la «francesita " Nathalie, que no eyacula porque « acabar es de obrero $»^{58}$.

67 A esa estrategia de autofiguración responde también la apropiación de la caritura del intelectual peronista que propone cierto estereotipo liberal antiperonista ("gorila», como se dice en Argentina). Piénsese por ejemplo en una anécdota recogida por el periodista Jorge Fernández Díaz -seguramente propalada por el propio Asís-, según la 
cual, poco después de la publicación de Flores robadas en los jardines de Quilmes, la crítica Beatriz Sarlo, al encontrárselo por casualidad en la editorial Losada, le dijo que no le había gustado la novela; a lo cual Asís habría respondido : "No me preocupa, Beatriz, vengo a cobrar los derechos de autor $\aleph^{59}$. En el mismo sentido podría interpretarse el coqueteo con el fascismo de Lesca... : como una forma de redoblar la apuesta frente a la acusación de «fascista » que siempre sobrevuela desde el campo liberal y algunas franjas de la izquierda contra el peronismo, agravada en el caso particular de Asís por la opinión, extendida entre vastos sectores de la intelectualidad de los '80, de que Flores robadas en los jardines de Quilmes fue « el best-seller de la dictadura » (Osvaldo Soriano incluso comparó a la obra de Asís con la literatura de éxito masivo bajo el nazismo ${ }^{60}$ ). Frente a la imputación de fascismo, Asís responde con la escritura de una novela-ensayo sobre la vida de un fascista. Podría decirse que estamos ante la vieja tradición popular argentina, con particular anclaje en el peronismo, de la reapropiación del insulto, de la cual son buenos exponentes el mote evitista « descamisado » o el nombre de la agrupación política « putos peronistas".

68 Ahora bien, para ser efectivo, este sistema de autofiguración parece demandar una cierta excentricidad con relación a la alta cultura. De allí que, cuando busca responder al imperativo de escribir una novela de "escritor latinoamericano en París ", Asís ofrezca sólo realizaciones ficcionales deficientes. En Dulces Otoñales (2014), en Del Flore a Montparnasse (2000), a causa de un uso trillado y poco hábil del «capital cultural », la escritura pierde interés. Solo se repite lo ya sabido : París como el lugar de una sexualidad feliz o diversificada, menciones de calles, el café del Flore, referencias al lujo. ¿Para qué hacer mal, de manera kitsch, lo que John Berger, por ejemplo, ya hizo bien?

Who lives in this mansion which is Paris? Every city has a sex and an age which have nothing to do with demography. Rome is feminine. So is Odessa. London is a teenager, an urchin, and, in this, hasn't changed since the time of Dickens.

Paris, I believe, is a man in his twenties in love with an older woman. ${ }^{61}$

69 Una singularización, entonces, la del « personaje Asís », que requiere de cierta distancia con la alta cultura : un "dandy suburbano », según lo definieran los entrevistadores de $\mathrm{El}$ ojo mocho. Una estrategia de autofiguración que se distingue de otras estrategias, que se diferencia de otros modelos posibles de dandi -cada uno, por lo demás, con su relación particular con París y la distinción cultural : el dandi " gentleman" (Miguel Cané, Eduardo Wilde), el dandi esteticista finisecular del modernismo latinoamericano (Darío, Julián del Casal) ${ }^{62}$, el modelo « epicúreo » de clase de alta de Adolfo Bioy Casares. De allí que para autofigurarse como «dandy» el "yo» de Memorias tergiversadas ${ }^{63}$ acuda al tango «Bailarín compadrito », de Miguel Bucino :

Vestido como dandy, peinao a la gomina y dueño de una mina más linda que una flor, bailás en la milonga con aire de importancia, luciendo la elegancia y haciendo exhibición.

Cualquiera iba a decirte, che, reo de otros tiempos, que un día llegarías a rey de cabaret, que pa' enseñar tu corte pondrías academia... Al taura siempre premia la suerte que es mujer.

(..)

Pero algo vos darías por ser sólo un ratito el mismo compadrito del tiempo que se fue, pues cansa tanta gloria y un poco triste y viejo te ves en el espejo del viejo cabaret. ${ }^{64}$ 
«Exhibición » y «aire de importancia » de un « reo de otros tiempos »: marcas de la autoconstrucción plebeya del dandi mediático, que se ha autodefinido como «un Berlusconi sin guita ${ }^{65}$. Porque si, como dice Julio Premat, para los Macedonio y los Borges, a partir de una cierta idea de autoconstrucción negativa, ser un "gran escritor " es «no ser nada o nadie ", para " el personaje Asís", por el contrario, ser escritor es « ser alguien»: de la «nadería de la personalidad» al panelismo en Animales sueltos ${ }^{66}$. La autofiguración se construye para persuadir no solamente al lector, sino también a la sociedad mediática. De allí la gestualidad histriónica, las fotos de las portadas de los libros, los primeros planos, durante las apariciones televisas, de las manos con ese enorme anillo azul, características todas que se oponen a la imagen televisiva que podía cultivar, por ejemplo, otro escritor paridigmáticamente mediático, Sabato ${ }^{67}$. Es otra forma de publicitarse, en el sentido de darse a conocer socialmente y de presentarse como mercancía. «El personaje Asís » no gana premios literarios ni participa del circuito de disertaciones universitarias. Tampoco suele hablar -con la notable de excepción de la entrevista de El ojo mocho- como escritor, tocando los temas típicos de la « entrevista de escritor» («la escena de escritura», «la escena de lectura», los "misterios de la creación », según Leonor $\left.\operatorname{Arfuch}^{68}\right)$. Más bien la «obra » sirve para fundar una palabra pública, de pretensiones políticas. Para lograr que circulen frases, definiciones sobre la política, rumores, tweets. En la era de la posautonomía, donde lo que prima es la indiferenciación generalizada entre literatura y no literatura, "el personaje Asís» propone una singularidad, justamente una diferencia: se presenta como el residuo paródico del «escritor-político » a la vieja usanza. Un «autor » que, validado por una « obra » que « lee la crítica » hace intervenciones políticas en el espacio público, tomando también algo de la figura clásica del tribuno satírico peronista.

71 Al momento en que se escriben estar líneas, el personaje está en su máximo esplendor : su autofiguración parece haber persuadido a los otros : el « yo » que se dice « escritor », es considerado « escritor» y desde allí construye un prestigio, casi una respetabilidad. La pose de dandi que sorprende pero nunca se sorprende -recordemos que uno de los atributos baudelaireanos del dandi es el estoicismo-, «rinde » ahora para explicar, en intervenciones televisivas, cómo es la política argentina o cuál es el sentido oculto de los entuertos de Medio Oriente. Ya no es ese personaje con bigotes paródicamente lugonianos, que debía representar, como ministro de cultura de un gobierno neoliberal, a un campo cultural que lo detestaba. Ahora el personaje detenta una posición de saber. Enuncia exposiciones más allá de la moralidad "progresista »-en realidad más allá de toda moralidad- ante un público dócil, en general puramente masculino, que gusta de que un hombre con « experiencia », «amigos importantes » $\mathrm{y}$ « data » lo « avive » acerca de " cómo se corta el bacalao». Dice «la posta», como si fuera una versión plebeya de Maquiavelo, filósofo a quien « el personaje Asís » cita con frecuencia.

72 Por su parte, la academia ha comenzado a leer la obra, más allá del obvio rechazo que produce la actuación de la figura pública, con episodios tales como el sórdido apoyo al indulto de 1990 para los militares genocidas de la última dictadura ${ }^{69}$. Ya no corre el «Peguémosle a Asís » del que hablaba Fogwill en 1983, ni se lo acusa, como hiciera un crítico de Punto de Vista de « chafalonería intelectual » ${ }^{70}$. En 2017, es de buen tono citarlo, casi un esnobismo agradable, y existe una discreta tradición crítica de la cual este mismo artículo forma parte: Horacio González y el equipo de El ojo mocho, Josefina Ludmer, Nélida Burgos, Juan Pablo Parchuc, Mario Guillhermo Massini, Nicolás Mavrakis, Elsa Drucaroff, Fernando Bogado, Alfredo Greco y Bavio, entre otros... ${ }^{71}$. 
73 Lo cierto es que como lo sabían muy bien los moralistas clásicos, las apariencias sociales son sumamente frágiles. A lo cual hay que sumar, en el caso particular de Asís, tan cercano al mundo de la política, el impacto de la Fortuna maquiaveliana en su versión argentina.

74 El poder sobre los otros que construye un "yo » a través de su imagen, la persuasión pública de su autofiguración, la " gloria » de la que habla el tango « Bailarín compadrito », es siempre inestable. Sic transit gloria « dandi » : un pequeño cambio en la cultura política, o en las condiciones de enunciación de los discursos públicos, puede provocar el derrumbe de la imagen (o su « descascaramiento », para usar otra palabra del vocabulario político asisiano). La representación del personaje podría entrar en crisis. En tal caso, el culto a la « amistad » comenzaría a ser visto como complicidad mafiosa, el maquiavelismo plebeyista como bastardeo y negación de lo político. La escena «barrial » masculina se interpretaría, en la misma línea, como un teatro misógino que refuerza todo tipo de opresiones de género y de clase. El conceptismo podría entenderse como vacío intelectual y la finta retórica como un timo ramplón e inmoral. Las ocurrencias, tan graciosas ahora, pasarían a ser arcaísmos desactivados. Queda por verse entonces si « el personaje Asís » podrá sostener su estrategia de singularización, o si por el contrario, " esnobeado » por las nuevas modas literarias, por los corrimientos culturales y políticos, del dandi « reventado » solo ha de resistir, apenas, el adjetivo.

\section{BIBLIOGRAPHY}

Amícola, José. Astrología y fascismo en Roberto Arlt. 2da. edición revisada y aumentada. Rosario: Beatriz Viterbo, 1994[1984].

AA.VV. Fascisme français? La controverse. Sous la direction de Serge Berstein et Michel Winock. Introduction de Jean-Noël Jeanneney. Paris: CNRS Éditions, 2014.

AA.VV. Qui parle n¹. vol. 13 (Fall/Winter 2001): «Fascism, Gender, and Culture».

Abraham, Tomás. «Un lago muerto en Asís», El amante. Buenos Aires, n 103, octubre de 2000, pp.30-31.

Aguinis, Marcos. La matriz del infierno. Buenos Aires: Sudamericana, 1997.

Antliff, Mark. Avant-Garde Fascism: The Mobilization of Myth, Art and Culture in France, 1909-1939. Durham: Duke University Press, 2007.

Arfuch, Leonor. El espacio biográfico. Dilemas de la subjetividad contemporánea. Buenos Aires: Fondo de Cultura Económica, 2002.

Arlt Roberto. Obra completa. Tomo uno. Buenos Aires: Planeta Carlos Lohle Biblioteca del Sur, 1991.

Asís, Jorge. Carne picada. Buenos Aires: Legasa, 1981.

Asís, Jorge. Dulces Otoñales. Buenos Aires: Sudamericana, 2014.

Asís, Jorge. Flores robadas en los jardines de Quilmes. Canguros I. Buenos Aires: Losada, 1980. 
Asís, Jorge. Lesca, el fascista irreductible. Buenos Aires: Sudamericana, 2000.

Asís, Jorge. Los reventados. Buenos Aires: Sudamericana, 1981 [1974].

Asís, Jorge. Memorias tergiversadas. Buenos Aires: Sudamericana, 2017.

Avellaneda, Andrés. «'Best-seller’ y código represivo en la narrativa argentina del ochenta: el caso Asís». Pittsburg. Revista Iberoamericana. octubre-diciembre 1983, no 125 v. XLIX, pp. 983-1008.

Baudelaire, Charles. Critique d'art, suivi de Critique musicale. Paris: Gallimard, 1992.

AA.VV. «Dossier sobre Jorge Asís». El ojo mocho. Buenos Aires. n 16, verano 2001/2.

Berger, John. Selected essays, New York: Vintage, 2003. [Ed. electrónica]

Bertrand Dorléac, Laurence. L'art de la défaite, 1940-1944. Paris: Seuil, 1993.

Bioy Casares, Adolfo. Borges. Barcelona: Destino, 2006.

Bogado, Fernando. «El «caso Asís". La construcción crítica del margen en la lectura de Flores robadas en los jardines de Quilmes», Actas del V Congreso Internacional de Letras (2012) de la FFyL-UBA, disponible en <http://2012.cil.filo.uba.ar/sites/2012.cil.filo.uba.ar/files/0064\%20BOGADO,\% 20FERNANDO.pdf>, página consultada el 15/05/2017.

Bolaño, Roberto. La literatura nazi en América. Barcelona: Seix Barral, 1996.

Brasillach, Robert. Notre avant-guerre (1941), en Euvres complètes. Première édition annotée par Maurice Bardèche. Tome VI. Paris: Club de l'honnête homme, 1964.

Bruneau, Jean-Baptiste. Le "cas Drieu». Drieu La Rochelle entre écriture et engagement. Débats, représentations et interprétations de 1917 à nos jours. Paris: Eurédit, 2011.

Bucino, Miguel. «Bailarín compadrito», Letra y música (1929).

Burgos, Nidia. Jorge Asís: los límites del canon. Prólogo de Pedro Luis Barcia. Buenos Aires: Catálogos, 2001.

Carnevali, Barbara. Le apparenze sociali. Una filosofia del prestigio. Bologne: Il Mulino, 2012.

Casanova, Pascale. La république mondiale des lettres. Paris: Seuil, 1999.

Céline, Louis Ferdinand. «À l'agité du bocal». Cahiers de l'Herne n5, 1965[1948].

Céline, Louis Ferdinand. Voyage au bout de la nuit. Paris: Folio, 1952 [1932].

Desanti, Dominique. Drieu La Rochelle: du dandy au nazi. Paris: Flammarion, 1992[1978].

Drieu la Rochelle, Pierre. Journal 1939-1945. Présenté et annoté par Julien Hervier. Paris : Gallimard, 1992.

Drieu la Rochelle, Pierre / Victoria Ocampo. Lettres d'un amour défunt. Correspondance 1929-1944. Édition établie par Julien Hervier. Paris: Sur-Bartillat, 2009.

Drucaroff, Elsa. Los prisioneros de la torre. Buenos Aires: Emecé, 2011.

Fernández Díaz, José. «El regreso del escritor maldito», La Nación, 7 de Octubre de 2012, disponible en <http://www.lanacion.com.ar/1515097-el-regreso-del-escritor-maldito>, página consultada el accedido el 15/05/2017.

Feinmann, José Pablo. La sombra de Heidegger. Buenos Aires: Seix Barral, 2005.

Fontanier, Pierre. Les figures du discours. Paris: Flammarion, 1977 
García, Mariano. «Ese jardín vedado al medio pelo. Capítulos del esnobismo en Victoria Ocampo, Adolfo Bioy Casares y Jorge Luis Borges ». Revista Lirico, número 16: "Esnobismos”. Disponible en https://lirico.revues.org/

Geiger, Wolfgang. L'image de la France dans l'Allemagne nazie : 1933-1945. Nouvelle édition [en ligne]. Rennes: Presses universitaires de Rennes, 1999, disponible en <http://books.openedition.org/ pur/9279>, página consultada el 15/04/2017.

Gramuglio, María Teresa. Nacionalismo y cosmopolitismo en la literatura argentina. Rosario: Editorial Municipal de Rosario, 2013.

Grieco y Bavio, Alfredo. «Habla, olvidadiza memoria. Sobre 'Memorias tergiversadas', la autobiografía de Jorge Asís», Revista Ñ. 03/04/2017, Disponible en <https://www.clarin.com/ revista-n/ideas/habla-olvidadiza-memoria_0_S1shT-eae.html>, página consultada el 15/05/2017.

Hervier, Julien. Deux individus contre l'histoire : Drieu La Rochelle et Ernst Jünger. Paris: Eurédit, 2010.

Huerta, Mona. «Un mediateur efficace pour la cooperation scientifique française: le groupement des universités et des grandes écoles de France pour les relations avec l'Amérique Latine», Encuentro de Latinoamericanistas Españoles (12. 2006. Santander): Viejas y nuevas alianzas entre América Latina y España. España: CEEIB. 2006, pp. 792-803. Disponible en <https://halshs.archivesouvertes.fr/halshs-00103840>, página consultada el 15/04/2017.

Jullian, Philippe, y otros. Dictionnaire du snobisme. Paris: Plon, 1958.

Jünger, Ernst. Der Kampf als inneres Erlebnis. Berlin: E.S. Mittler \& Sohn, 1922.

Kaplan, Alice Yaeger. Reproductions of Banality: Fascism, Literature, and French Intellectual Life. Minneapolis: Minnesota U P, 1986.

Lacroix, Michel. «Lien social, idéologie et cercles d'appartenance : le réseau 'latin' des Québécois en France, 1923-1939.», Études littéraires. 36, n² 2, 2004, pp. 51-70, disponible en < https:// www.erudit.org/fr/revues/etudlitt/2004-v36-n2-etudlitt1133/012903ar/ > página consultada el 15/04/2017.

Lesca, Charles. Quand Israël se venge. Paris: Grasset, 1941.

Loiseaux, Gérard. La littérature de la défaite et de la collaboration d'après Phönix oder Asche? (Phénix ou cendres?) de Bernhard Payr. Paris: Université Paris I, Publications de la Sorbonne, 1984.

López, María Pía y Korn, Guillermo. Sabato, o la moral de los argentinos. Buenos Aires: América Libre, 1997.

Loubet del Bayle, Jean-Louis. Les non-conformistes des années 30 : une tentative de renouvellement de la pensée politique française. Paris; Éditions du Seuil, 2001[1969].

Ludmer, Josefina. Aquí América latina. Una especulación. Buenos: Eterna cadencia, 2010.

Ludmer, Josefina. «Literaturas postautónomas 2.0», Propuesta Educativa. Buenos Aires: FLACSO. Núm. 32, Año 18, Vol. 2, pp. 41-45, Disponible en <http://www.redalyc.org/articulo.oa? id=403041704005>, fecha de consulta 15/04/2017.

Marimón, Antonio. «Un best-seller argentino: las mil caras de un pícaro». Punto de vista. Buenos Aires. n¹4, marzo-julio de 1982, pp.24-27.

Massini, Mario Guillhermo. «La manifestación y después. Autofiguración y mitificación de escritor en Jorge Asís leída en clave bordieuana.», Temáticas. Campinas. 21(41), enero/junio, 2013, pp.17-41. 
Mavrakis, Nicolás. «La literatura de Jorge Asís», Revista Paco. 27 de julio de 2015, disponible en https://revistapaco.com/2015/07/27/la-literatura-de-jorge-asis/, página consultada el 15/05/2017.

Michaud, Eric. La estética nazi. Un arte para la eternidad. Buenos Aires: Adriana Hidalgo, 2009.

Molloy, Sylvia. Poses de fin de siglo. Desbordes del género en la modernidad. Buenos Aires: Eterna Cadencia, 2012.

Montandon, Alain, y otros. Dictionnaire du dandysme. Paris: Honoré Champion, 2016.

Mosse, George L. Das Bild des Mannes. Zur Konstruktion der modernen Männlichkeit. Frankfurt a.M: Büchergilde Gutenberg, 1997.

Muel-Dreyfus, Francine. Vichy et l'éternel féminin. Contribution à une sociologie politique de l'ordre des corps. Paris: Seuil, 1996.

Neaman, Elliot Yale. «Warrior or Esthete? Reflections on the Jünger Reception in France and Germany.». New German Critique, 1993, n 59, 1993.

Parchuc, Juan Pablo. «Contar desde el borde: literatura argentina y peronismo en Jorge Asís». Badebec. Vol. 4 n 7 (Septiembre 2014), pp. 109-135. Disponible en http://www.badebec.org/sitio/ pdf/articulos_parchuc_7.pdf, accedido el 15/05/2017.

Posse, Abel. Biblioteca esencial: 101 libros fundamentales de la literatura mundial, con un anexo sobre literatura argentina y rioplatense. Buenos Aires: Emecé, 1991.

Posse, Abel. El viajero de Agartha. Buenos Aires: Emecé, 1989.

Posse, Abel. En letra grande. Buenos Aires: Emecé, 2005,

Posse, Abel. Los demonios ocultos. Buenos Aires: Emecé, 1987.

Premat, Julio. Héroes sin atributos: figuras de autor en la literatura argentina. Buenos Aires: Fondo de Cultura Económica, 2009.

Rebatet, Lucien. Les décombres. Paris: Denoël, 1942.

Rein, Raanan. Los muchachos peronistas judíos. Los argentinos judíos y el apoyo al Justicialismo. Buenos Aires: Sudamericana, 2015

Sapiro, Gisèle. La guerre des écrivains. Paris: Fayard, 1999.

Senkman, Leonardo y Sosnowski, Saúl. Fascismo y nazismo en las letras argentinas. Buenos Aires: Ediciones lumiere, 2009.

Sigal, Silvia y Verón, Eliseo. Perón o muerte. Los fundamentos discursivos del fenómeno peronista. Buenos Aires: EUDEBA, 2003 [1986].

Soriano, Osvaldo. Entrevista de Rosa María Pereda en El país: «'El gran problema argentino es la falta de memoria histórica'. Acaba de aparecer su novela 'Cuarteles de invierno'», 20 de abril de 1982. Disponible en <http://elpais.com/diario/1982/04/20/cultura/388101612_850215.html>, accedido el 15/05/2017.

Terray, Aude. Les derniers jours de Drieu La Rochelle. Paris: Grasset, 2016.

Thackeray, William Makepeace. The Book of Snobs and Other Contributions to Punch. London: Macmillan, 1911.

Theweleit, Klaus. Männerphantasien (2 vol.). Frankfurt a.M.: Roter Stern, 1977-8. 
Traverso, Enzo. À feu et à sang : De la guerre civile européenne 1914-1945. Paris: Éditions Stock, 2007 [Ed. electrónica].

Vanoosthuyse, Michel. «Ernst Jünger, itinéraire d'un fasciste clean. Dernières publications, derniers masques». Agone, 2/2014, $\mathrm{n}^{\circ} 54$.

\section{NOTES}

1. Agradezco a Magdalena Cámpora, con quien he discutido todas estas ideas.

2. Alain Montandon y otros, Dictionnaire du dandysme, Paris: Honoré Champion, 2016; Philippe Jullian y otros, Dictionnaire du snobisme, Paris: Plon, 1958.

3. Para un abordaje filosófico del prestigio y las apariencias sociales, véase Barbara Carnevali, Le apparenze sociali. Una filosofia del prestigio, Bologne: Il Mulino, 2012.

4. Mariano García, «"Ese jardín vedado al medio pelo”. Capítulos del esnobismo en Victoria Ocampo, Adolfo Bioy Casares y Jorge Luis Borges », Cuadernos LIRICO. http://lirico.revues.org/347

5. Philippe Jullian y otros, op. cit., s.v. «Argentine», pp. 30-31.

6. Charles Baudelaire, Critique d'art, suivi de Critique musicale, Paris: Gallimard, 1992, p. 369-372.

7. Charles Baudelaire, op.cit. , p. 372.

8. Ver por ejemplo, Julien Hervier, Deux individus contre l'histoire: Drieu la Rochelle et Ernst Jünger, Paris: Eurédit, 2010 o Aude Terray, Les derniers jours de Drieu la Rochelle, Paris: Grasset, 2016. Para una historia de las lecturas de Drieu, ver Jean-Baptiste Bruneau, Le «cas Drieu». Drieu la Rochelle entre écriture et engagement. Débats, représentations et interprétations de 1917 à nos jours, Paris: Eurédit, 2011 (son de particular interés para nuestra discusión las pp. 227-308).

9. Para la construcción de la figura de Ernst Jünger después la Segunda Guerra, ver Elliot Yale Neaman, «Warrior or Esthete? Reflections on the Jünger Reception in France and Germany.», New German Critique, 1993, n 59, pp. 118-50. También en el mismo sentido, para la mitologización de Jünger como «nazi antinazi» o «fascista clean», véase Michel Vanoosthuyse, «Ernst Jünger, itinéraire d'un fasciste clean. Dernières publications, derniers masques», Agone, 2/2014, $\mathrm{n}^{\circ} 54$.

10. Por ejemplo: «Drieu la Rochelle, 'Jeune européen' en 1927, 'socialiste fasciste' en 1934, est un témoin-symbole de l'étroitesse du chemin. Sa vie reste aussi un document rare sur tous les courants, tous les égarements du début de ce siècle qui s'achève. Il nous propose ses amours, son incompréhension des êtres, et particulièrement des femmes, ses aberrations d'une politique chaque fois choisie au gré des passions, comme un avatar de don Juan et une incarnation toujours actuelle de ceux qui cherchent à compenser leur faiblesse cachée en adorant la force déclarée.» Dominique Desanti, Drieu la Rochelle: du dandy au nazi, Paris: Flammarion, 1992, p. 6.

11. Para el uso de la sátira en Asís, véase Carlos Belvedere, «Parodia y sátira en dos poéticas peronistas», Buenos Aires, El ojo mocho, n 16, verano 2001/2. Para la idea de «reviente» asisiano, véase Esteban Rodríguez y Fernando Alfón Scafati, «Voladuras. (Historia, aventura y resignación)», Ibidem.

12. Horacio González, «La figura literaria del reventado como teoría picaresca de la política», Buenos Aires, El ojo mocho, n 16, verano 2001/2, p. 32.

13. Robert Brasillach, Notre avant-guerre, en Cuvres complètes. Première édition annotée par Maurice Bardèche. Tome VI, Paris: Club de l'honnête homme, 1964[1941], p. 211.

14. Robert Brasillach, op. cit., p. 217.

15. Louis Ferdinand Céline, Voyage au bout de la nuit, Paris: Folio, 1952, p. 106.

16. Según el anecdotario borgeano recogido por Bioy Casares, Borges utilizaba la figura de Capvedila de forma humorística para referirse al bajo valor literario: «Borges recuerda para [Norman Thomas] Di Giovanni la frase de Mastronardi: 'No me cabe un capdevila de duda', y explica: 'Toma a Capdevila como la mínima unidad de medida: aseguraba que ya se empleaba el 
nombre de nuestro polígrafo para indicar cantidades mínimas o negligibles.'» Adolfo Bioy Casares, Borges, Barcelona: Destino, 2006, p.1251. En Lesca, el «capdevila» ya no sirve para designar el bajo valor literario de algunas obras, sino la anulación de toda atribución de valor literario, su disolución en la economía, y de paso, para pegarle a los escritores de la izquierda (Barletta, Yunque). Este giro economicista de la metáfora de los «capdevilas» tiene todo el aire de ser un aporte de Asís. Por lo demás, la mención anacrónica a «Álvarez Tuñón» es una marca de montaje: este nombre parece referir al escritor Eduardo Álvarez Tuñon, a quien Asís menciona en sus crónicas de Oberdán Rocamora, el cual, si partimos de la idea de que el «discipulado» es una relación siempre personal, en tête-à-tête, díficilmente podría considerarse «un discípulo de Lugones», dado que nació 1957. La elección del nombre quizá se deba a su cercanía con el nombre del poeta de izquierdas González Tuñón, quien, nacido en 1904, sí llegó a ser contemporáneo de Lugones, aunque jamás fue, obviamente, su discípulo.

17. Véase también: «El antisemitismo periodístico presentaba inexplorados atractivos comerciales e interesaba en todos los mercados emergentes», op. cit., p.111.

18. Ver, sobre este tema, Wolfgang Geiger, L'image de la France dans l'Allemagne nazie: 1933-1945. Nouvelle édition [en ligne], Rennes : Presses universitaires de Rennes, 1999, disponible en <http:// books.openedition.org/pur/9279>, accedido el 15/04/2017.

19. Gérard Loiseaux, La littérature de la défaite et de la collaboration d'après Phönix oder Asche? (Phénix ou cendres?) de Bernhard Payr, Paris: Université Paris I, Publications de la Sorbonne, 1984, pp. 177-178.

20. Robert Brasillach, op. cit., p. 214.

21. Gisèle Sapiro, La guerre des écrivains, Paris: Fayard, 1999, p.9.

22. Zuleta Álvarez está primero y más arriba en la dedicatoria de la novela, diferenciándose así de los otros dedicatarios: funcionarios menemistas, intelectuales y amigos personales de Asís.

23. María Teresa Gramuglio, Nacionalismo y cosmopolitismo en la literatura argentina, Rosario: Editorial Municipal de Rosario, 2013, p. 244.

24. María Teresa Gramuglio, op. cit., p. 244.

25. Para la idea de narrador «crudista», ver Esteban Rodríguez y Fernando Alfón Scafati, ibidem.

26. Véase también el $n^{\circ} 1$. vol. 13 (Fall/Winter 2001), con el tema «Fascism, Gender, and Culture» de la revista Qui parle.

27. Enzo Traverso, À feu et à sang : De la guerre civile européenne 1914-1945, Paris: Éditions Stock, 2007, 443,3/675 (Ed. electrónica)

28. Véase Eric Michaud, La estética nazi. Un arte para la eternidad. Buenos Aires, Adriana Hidalgo, 2009.

29. Roberto Arlt, Obra completa. Tomo uno, Buenos Aires: Planeta Carlos Lohle Biblioteca del Sur, 1991, p. 129.

30. Ernst Jünger, Der Kampf als inneres Erlebnis, Berlin: E.S. Mittler \& Sohn, 1922, p.33.

31. Pierre Drieu la Rochelle, Journal 1939-1945. Présenté et annoté par Julien Hervier, Paris : Gallimard, 1992, p.203.

32. Céline, Louis Ferdinand, «À l'agité du bocal», Cahiers de l'Herne n 5 , 1965, pp. 22-24.

33. «Avec lui, aucune équivoque. Venu de plusieurs bandes de réfractaires et de radicaux toulousains fort débraillés dans leurs convictions, il n'avait pas à secouer comme nous des scrupules d'hommes de droite. Aucun débris de dogmes ne l'embarrassait. On peut dire qu'il s'était rallié à nous d'instinct, en 1936, du jour où ses amis démocrates avaient commencé d'agiter le boute-feu. Pas le moindre débat de conscience dans son cas, pas une seule de ces ridicules bouffées de chaleur que nous avions presque tous à confesser.», Lucien Rebatet, Les décombres, Paris: Denoël, 1942, pp.129-130.

34. «En 1944 et 1945, une nouvelle représentation se juxtapose à celle, plus ancienne, de la femme violée : la 'collaboratrice horizontale'. De sanctuaire profané, son corps se mue en source de péché et en honte nationale dont la punition passe inévitablement à la fois par la 
stigmatisation morale et par l'humiliation physique : la tonte comme spectacle populaire», Enzo Traverso, À feu et à sang : De la guerre civile européenne 1914-1945, Paris: Éditions Stock, 2007, 450,5-451,3/675 (Ed. electrónica)

35. Véase el tango «Tortazos», de 1930 (letra de Enrique Maroni, música de José Razzano).

36. Louis Ferdinand Céline, Voyage au bout de la nuit, Paris: Folio, 1952, p.103.

37. Véase por ejemplo con la descripción de Lesca que da Rebatet en Les décombres: «Quelques mois après, Je Suis Partout marchait gaillardement d'un pied neuf, avec une petite troupe de nouveaux venus : Charles Lesca, notre administrateur, majestueux, souriant, d'un courage politique que rien ne devait ébranler», Lucien Rebatet, op. cit., p.20; «Aussi calme et égal que Laubreaux était impétueux, notre ami et aîné Charles Lesca, volontaire de l'autre guerre, bel homme solidement assis dans la vie et dans ses convictions, administrateur devenu rédacteur en chef dans l'absence de Brasillach, nous apportait le précieux concours de sa sereine dignité, épousait sans la moindre réticence nos plus périlleuses querelles, portait en tous lieux son flegmatique mépris pour l'abjecte aventure et les marionnettes en bouchons qu'elle roulait.» Lucien Rebatet, op. cit., p.130.

38. Pierre Drieu la Rochelle / Victoria Ocampo, Lettres d'un amour défunt. Correspondance 1929-1944. Édition établie par Julien Hervier.

39. Josefina Ludmer. Aquí América latina. Una especulación, Buenos: Eterna cadencia, 2010, pp. 79-80.

40. Entrevista a Jorge Asís hecha por Horacio González, Christian Ferrer, Eduardo Rinesi, Esteban Vernik, María Pía López y Facundo Martínez en Buenos Aires: El ojo mocho, n 16, verano 2001/2., p.20.

41. Pierre Fontanier, Les figures du discours, Paris: Flammarion, 1977, p. 429.

42. «En Lesca (en la memoria neoliberal) lo más notable es la desdiferenciación. Primero entre realidad y ficción: no se sabe si los personajes son todos reales o no, no se sabe si es novela (tal como se presenta el texto) o ensayo histórico o político, o biografía o simplemente una historia del presente. No hay diferenciación entre realidad y ficción y tampoco entre la derecha y la izquierda (el fascismo y el comunismo son el mismo horror). Lesca es la versión neoliberal de 'los dos demonios' (comunismo y fascismo = guerrilla y dictadura militar), un texto sobre la desdiferenciación de las dos fuerzas enfrentadas en los años de 1970.» Josefina Ludmer, op. cit., p. 78.

43. Jean-Louis Loubet del Bayle, Les non-conformistes des années 30 : une tentative de renouvellement de la pensée politique française, Paris; Éditions du Seuil, 2001[1969].

44. Mona Huerta, «Un mediateur efficace pour la cooperation scientifique française: le groupement des universités et des grandes écoles de France pour les relations avec l'Amérique Latine», Encuentro de Latinoamericanistas Españoles (12. 2006. Santander): Viejas y nuevas alianzas entre América Latina y España, s.l., España: CEEIB, 2006, pp.792-803. Disponible en <https:// halshs.archives-ouvertes.fr/halshs-00103840>, accedido el 15/04/2017.

45. Michel Lacroix, «Lien social, idéologie et cercles d'appartenance: le réseau "latin" des Québécois en France, 1923-1939.» Études littéraires 36, n² 2, 2004, pp. 51-70. Disponible en < https://www.erudit.org/fr/revues/etudlitt/2004-v36-n2-etudlitt1133/012903ar/ > accedido el 15/04/2017.

46. Véase Mark Antliff, Avant-Garde Fascism: The Mobilization of Myth, Art and Culture in France, 1909-1939, Durham: Duke University Press, 2007.

47. Pierre Drieu la Rochelle, op.cit., p.320.

48. Nótese de paso el uso del verbo « defraudar », de clara connotación menemista... ¿un guiño al ex presidente y a algunos de los dedicatarios de la novela?

49. Por lo demás, véase sobre este tema la excelente investigación de Raanan Rein, Los muchachos peronistas judios. Los argentinos judíos y el apoyo al Justicialismo, Buenos Aires: Sudamericana, 2015.

50. Abel Posse, En letra grande, Buenos Aires: Emecé, 2005, p. 266. 
51. Véase el mencionado Geiger y Laurence Bertrand Dorléac, L'art de la défaite, 1940-1944, Paris: Seuil, 1993.

52. Senkman y Sosnowski, op.cit. 119-127.

53. Ver al respecto AA.VV., Fascisme français? La controverse. Sous la direction de Serge Berstein et Michel Winock. Introduction de Jean-Noël Jeanneney, Paris: CNRS Éditions, 2014.

54. Entrevista a Jorge Asís hecha por Horacio González, Christian Ferrer, Eduardo Rinesi, Esteban Vernik, María Pía López y Facundo Martínez en Buenos Aires: El ojo mocho, n 16, verano 2001/2., p.10.

55. «Asís encontró su espejo gracias a su viaje a París, lo vio en Lesca», Tomás Abraham, «Un lago muerto en Asís», Buenos Aires: El amante, n 103, octubre de 2000, pp.31.

56. Jorge Asís, Flores robadas en los jardines de Quilmes. Canguros I, Buenos Aires: Losada, 1980, p.45.

57. Jorge Asís, Memorias tergiversadas, Buenos Aires: Sudamericana, 2017, p.100.

58. Jorge Asís, Dulces Otoñales, Buenos Aires, Sudamericana, 2014, p.30.

59. José Fernández Díaz, «El regreso del escritor maldito», Nota en La Nación, 7 de octubre de 2012. Disponible en <http://www.lanacion.com.ar/1515097-el-regreso-del-escritor-maldito>, accedido el accedido el 15/05/2017.

60. Osvaldo Soriano, entrevista de Rosa María Pereda en El País, «'El gran problema argentino es la falta de memoria histórica'. Acaba de aparecer su novela 'Cuarteles de invierno'», 20 de abril de 1982. Disponible en <http://elpais.com/diario/1982/04/20/cultura/388101612_850215.html>, accedido el 15/05/2017. Véase también Andrés Avellaneda, «'Best-seller' y código represivo en la narrativa argentina del ochenta: el caso Asís», Pittsburg, Revista Iberoamericana, octubrediciembre 1983, no 125, v. XLIX, pp. 983-1008.

61. John Berger, «Imagine Paris» en Selected essays, New York: Vintage, 2003. [Ed. electrónica 1206,1 / 1367]

62. Véase AA.VV. Cielo dandi. Escrituras y poéticas de estilo en América latina (Selección y prólogo de Juan Pablo Sutherland). Buenos Aires: Eterna Cadencia, 2011.

63. Jorge Asís, Memorias tergiversadas, Buenos Aires: Sudamericana, 2017, p.56-57.

64. «Bailarín compadrito», Letra y música de Miguel Bucino, (1929).

65. Jorge Asís, «Soy un Berlusconi sin plata», Entrevista en revista Gente, Buenos Aires, 30 de junio de 1994, por Patricia Barral, citada en Burgos, Nidia. Jorge Asís. Los límites del canon. Buenos Aires: Catálogos, 2001, p.238.

66. Julio Premat, Héroes sin atributos: figuras de autor en la literatura argentina, Buenos Aires: Fondo de Cultura Económica, 2009, p.15.

67. María Pia López y Guillermo Korn, Sabato, o la moral de los argentinos, Buenos Aires: América Libre, 1997.

68. Leonor Arfuch, El espacio biográfico. Dilemas de la subjetividad contemporánea, Buenos Aires: Fondo de Cultura Económica, 2002, pp. 157-176

69. Elsa Drucaroff hace un buen resumen de la actuación política y literaría de Asís: «Jorge Asís (1946) fue militante de la Federación Juvenil Comunista y en esa época comenzó a publicar ficción. Sus primeros libros, La manifestación (1971), Don Abdel Zalim (1972), Los reventados (1974), tuvieron en general buena acogida de la crítica (Los reventados fue primera mención en Casa de las Américas); trabajaban con su pasado familiar, su origen cultural y la militancia de izquierda. Fue periodista en el diario Clarín, donde escribía exitosas y notables aguafuertes que firmaba con el seudónimo Oberdan Rocamora. Luego del éxito de la trilogía Canguros-Flores robadas en los jardines de Quilmes (1980), Carne picada (1981) y La calle de los caballos muertos (1982)-, Asís publica Diario de la Argentina, una novela paródica donde desnuda la redacción de Clarín, que él mismo había integrado, y los negocios políticos y personales de los propietarios del poderoso medio. Este libro le valió el repudio y el silenciamiento por parte del matutino, cuya influencia sobre los sectores de poder argentinos era inmensa. En 1983 publica una cuarta novela, transformando la trilogía en tetralogía: Canguros III, pero ya no se vende como se esperaba. 
En 1988 Jorge Asís se aproxima a Carlos Saúl Menem, participa activamente a su lado en las elecciones internas que enfrentan a Antonio Cafiero y a Menem para decidir el candidato del Partido Justicialista. Tras la victoria electoral de Menem, en 1989, Asís se transforma en embajador argentino ante la UNESCO, y reside en París. Abandona esta ciudad y el cargo en 1994 para ocupar la Secretaría de Cultura de la Nación del menemato. Luego de una gestión breve y accidentada, de menos de un año, se dirige personalmente al presidente ante las cámaras de televisión para comunicarle su renuncia. La disidencia pasaba por una propuesta del escritor: regular las palabras en inglés en la vía pública. A pesar del enfrentamiento mediático, Menem lo nombra embajador argentino en Portugal, cargo que ocupa hasta la asunción del gobierno de De la Rúa, en 1999. Cuando el ex presidente es detenido, acusado de graves casos de corrupción (tráfico de armas), Asís es uno de los pocos políticos que mantiene lealtad a quien lo favoreció en el pasado y va a visitarlo. En las elecciones en las que triunfó Crisitna Kirchner (octubre 2007), hubo algunos intentos de agrupar una fórmula que defendiera la experiencia de los años 90. Uno de ellos fue la fórmula Jorge Sobisch-Jorge Asís: el escritor fue candidato a vicepresidente en la fórmula encabezada por el ex gobernador de Neuquén. Con su habitual desparpajo, Asís reconoció en cámara que había sufrido una derrrota impiadosa. Durante el kirchnerismo, el escritor rompió espadas una y otra vez con la nueva corrección política y los discursos izquierdizantes, defendiendo sus acciones menemistas.» (Elsa Drucaroff, Los prisioneros de la torre, Buenos Aires: Emecé, 2011, p.146).

70. Antonio Marimón, «Un best-seller argentino: las mil caras de un pícaro», Buenos Aires, Punto de vista, $\mathrm{n}^{\circ} 14$, marzo-julio de 1982, pp.24-27.

71. Elsa Drucaroff, Los prisioneros de la torre, Buenos Aires: Emecé, 2011; Nicolás Mavrakis, «La literatura de Jorge Asís» en Revista Paco, 27 de julio de 2015. Disponible en https:// revistapaco.com/2015/07/27/la-literatura-de-jorge-asis/, accedido el 15/05/2017. ; Mario Guillhermo Massini, «La manifestación y después. Autofiguración y mitificación de escritor en Jorge Asís leída en clave bordieuana.», Temáticas, Campinas, 21(41), enero/junio, 2013, pp.17-41. ; Fernado Bogado, «El «caso Asís". La construcción crítica del margen en la lectura de Flores robadas en los jardines de Quilmes», Actas del V Congreso Internacional de Letras (2012) de la FFyL-UBA. Disponible en http://2012.cil.filo.uba.ar/sites/2012.cil.filo.uba.ar/files/0064\% 20BOGADO,\%20FERNANDO.pdf accedido el 15/05/2017.; Juan Pablo Parchuc, «Contar desde el borde: literatura argentina y peronismo en Jorge Asís», Badebec, Vol. $4 \mathrm{n}^{\circ} 7$ (Septiembre 2014), pp. 109-135. Disponible en http://www.badebec.org/sitio/pdf/articulos_parchuc_7.pdf, accedido el 15/05/2017.Alfredo Grieco y Bavio, «Habla, olvidadiza memoria. Sobre 'Memorias tergiversadas', la autobiografía de Jorge Asís», Revista Ñ, 03/04/2017. Disponible en <https:// www.clarin.com/revista-n/ideas/habla-olvidadiza-memoria_0_S1shT-eae.html>, accedido el 15/05/2017.

\section{ABSTRACTS}

This paper analyzes the way the extreme right builds its own form of snobisme throught idealized representations of war and extermination. Is it possible to define a snobisme particular to violence and fascism? And how can this be read from a Latin American perspective? To reflect 
on these questions, we will analyze Lesca, el fascista irreductible (2000) by Jorge Asís, a novel that fictionalizes the relations between French and Argentine fascisms. We will particularly examine certain transatlantic connections suggested by the novel, that associate Maurras with Perón, Drieu la Rochelle with Victoria Ocampo, Vichy with neoliberalism, Céline and Rebatet with the Asís' own representation as a writer.

El presente trabajo analiza el esnobismo de la extrema derecha, que construye su estrategia de diferenciación recurriendo a representaciones enaltecedoras de la guerra y del aniquilamiento del otro. ¿Cómo definir el esnobismo de la violencia y del fascismo? ¿Cómo se representa ese esnobismo desde una perspectiva latinoamericana? Para reflexionar sobre estas cuestiones, analizaremos Lesca, el fascista irreductible (2000) de Jorge Asís, que ficcionaliza las relaciones entre los fascismos francés y argentino. Nos detendremos particularmente en las diversas conexiones que sugiere la novela, que van de Maurras a Perón, de Drieu la Rochelle a Victoria Ocampo, de Vichy al neoliberalismo, de Céline y Rebatet a la propia figura de autor de Asís.

Ce travail analyse le snobisme de l'extrême droite, qui construit sa propre stratégie de différenciation à partir de représentations idéalisées de la guerre et de l'anéantissement de l'autre. Comment définir un snobisme propre à la violence et au fascisme? Et comment ce snobisme peut-il être représenté d'un point de vue latino-américain? Pour réflechir à ces questions, nous analyserons Lesca, el fascista irreductible (2000) de Jorge Asís, un roman qui fictionnalise les relations entre les fascismes Français et Argentin. Nous nous occuperons des rapports transatlantiques suggérés par le texte, notamment ceux qui lient Maurras et Perón, Drieu la Rochelle et Victoria Ocampo, Vichy et le néolibéralisme, Céline et Rebatet avec la figure d'auteur d'Asís.

\section{INDEX}

Palabras claves: fascismo, esnobismo, relaciones Francia-Argentina, representaciones de la violencia

Mots-clés: fascisme, snobisme, relations France-Argentine, représentations de la violence Keywords: fascism, snobisme, France-Argentina relations, representations of violence

\section{AUTHOR}

\section{MARIANO SVERDLOFF}

Mariano Sverdloff es investigador del CONICET y docente de la cátedra de Literatura del Siglo XIX de la Facultad de Filosofía y Letras de la Universidad de Buenos Aires. Coordina la colección Colihue Clásica. marianosverdloff@gmail.com 